\title{
MINDFULNESS-BASED SYMPTOM MANAGEMENT AND THE TREATMENT OF BURNOUT
}

\author{
by \\ Catherine Adriana Shaw

\begin{abstract}
A thesis submitted to
the Faculty of Graduate and Postdoctoral Affairs in partial fulfillment of the requirements for the degree of

Master of Arts

in

Psychology
\end{abstract}

Carleton University

Ottawa, Canada

C2012 Catherine Adriana Shaw 
Library and Archives

Canada

Published Heritage

Branch

395 Wellington Street

Ottawa ON K1A ON4

Canada
Bibliothèque et

Archives Canada

Direction du

Patrimoine de l'édition

395 , rue Wellington

Ottawa ON K1A ON4

Canada
Your file Votre référence

ISBN: 978-0-494-93614-6

Our file Notre référence

ISBN: $978-0-494-93614-6$
NOTICE:

The author has granted a nonexclusive license allowing Library and Archives Canada to reproduce, publish, archive, preserve, conserve, communicate to the public by telecommunication or on the Internet, loan, distrbute and sell theses worldwide, for commercial or noncommercial purposes, in microform, paper, electronic and/or any other formats.

The author retains copyright ownership and moral rights in this thesis. Neither the thesis nor substantial extracts from it may be printed or otherwise reproduced without the author's permission.
AVIS:

L'auteur a accordé une licence non exclusive permettant à la Bibliothèque et Archives Canada de reproduire, publier, archiver, sauvegarder, conserver, transmettre au public par télécommunication ou par l'Internet, prêter, distribuer et vendre des thèses partout dans le monde, à des fins commerciales ou autres, sur support microforme, papier, électronique et/ou autres formats.

L'auteur conserve la propriété du droit d'auteur et des droits moraux qui protege cette thèse. $\mathrm{Ni}$ la thèse ni des extraits substantiels de celle-ci ne doivent être imprimés ou autrement reproduits sans son autorisation.
In compliance with the Canadian Privacy Act some supporting forms may have been removed from this thesis.

While these forms may be included in the document page count, their removal does not represent any loss of content from the thesis.
Conformément à la loi canadienne sur la protection de la vie privée, quelques formulaires secondaires ont été enlevés de cette thèse.

Bien que ces formulaires aient inclus dans la pagination, il n'y aura aucun contenu manquant. 


\begin{abstract}
This research examined participation in an 8-week mindfulness-based intervention for the treatment of burnout. Pre-course measures assessed symptoms of burnout and levels of self-compassion. Burnout, self-compassion, and levels of mindfulness practice were also measured at post- course and at a 3-month follow-up to examine the relationships between changes in these measures and also the effects of mindfulness practice on course outcomes. Overall, symptoms of burnout were reduced significantly, namely exhaustion, and levels of self-compassion increased significantly at post-course. These improvements were maintained at the 3-month follow-up for exhaustion and for each self-compassion subscale except for self-judgment, which increased significantly. Decreases in another aspect of burnout, cynicism, were also significant from post-course to 3-month follow-up. Lastly, no clear pattern emerged concerning the effects of mindfulness practice in relation to intervention outcomes.
\end{abstract}




\section{Acknowledgements}

With thanks and gratitude to all of the OMC course graduates who participated in this research project. The generosity with which you shared your experiences is what made this project interesting and worthwhile.

To Dr. Lynette Monteiro and Dr. Frank Musten, who founded the Ottawa Mindfulness Clinic in 2003. Thank you both for the many opportunities you have provided me over the past several years. None of this would have been possible without your openness to sharing with me your ideas and insights which form the foundation of this research. Thank you both for helping me to find the confidence to persevere through the many ups and downs of academic life.

To Dr. Craig Leth-Steensen, who was especially helpful when I most needed assistance. Thank you for your willingness to see this project through to completion. Your many contributions significantly improved the quality of this work.

To my friend, Mary Ann Foley. Your wisdom and guidance has shaped the course of my life well beyond the music lessons.

To my parents, James and Roswitha. Thank you both for your love and support, and for providing your children with the opportunities to lead purposeful lives.

"It is a bit embarrassing to have been concerned with the human problem all one's life and find at the end that one has no more to offer by way of advice than, 'Try to be a little kinder'." - Aldous Huxley 


\section{Table of Contents}

$\begin{array}{ll}\text { Title Page } & \text { i }\end{array}$

$\begin{array}{ll}\text { Abstract } & \text { ii }\end{array}$

$\begin{array}{ll}\text { Acknowledgements } & \text { iii }\end{array}$

Table of Contents $\quad$ iv

List of Tables vii

List of Figures $\quad$ ix

List of Appendices $\quad \mathbf{x}$

List of Abbreviations $\quad$ xi

Mindfulness-Based Symptom Management and the Treatment of Burnout $\quad 1$

Burnout 2

Mindfulness: Definition and Efficacy 6

Mindfulness-Based Interventions as Treatment for Burnout 9

$\begin{array}{ll}\text { Rationale for the Current Study } & 12\end{array}$

Examining the effects of mindfulness practice 13

Follow-up effects and mindfulness practice $\quad 15$

$\begin{array}{ll}\text { Mindfulness and self-compassion } & 17\end{array}$

$\begin{array}{ll}\text { Some Methodological Issues } & 18\end{array}$

$\begin{array}{ll}\text { The Current Study } & 20\end{array}$

$\begin{array}{ll}\text { Overview of the hypotheses } & 21\end{array}$

$\begin{array}{ll}\text { Method } & 21\end{array}$

$\begin{array}{ll}\text { Procedure } & 21\end{array}$

$\begin{array}{ll}\text { Description of the MBSM program } & 21\end{array}$ 
Participants

$\begin{array}{ll}\text { Measures } & 24\end{array}$

Maslach Burnout Inventory $\quad 24$

$\begin{array}{ll}\text { Self-Compassion Scale } & 25\end{array}$

$\begin{array}{ll}\text { Practice Survey } & 27\end{array}$

$\begin{array}{ll}\text { Results } & 28\end{array}$

$\begin{array}{ll}\text { Sample Characteristics } & 28\end{array}$

$\begin{array}{ll}\text { Data Screening } & 29\end{array}$

Pre- and Post-Intervention Sample $\quad 31$

$\begin{array}{ll}\text { Main variable outcomes } & 31\end{array}$

Correlations between measures $\quad 32$

$\begin{array}{ll}\text { Correlations between change scores } & 34\end{array}$

$\begin{array}{ll}\text { Practice effects } & 35\end{array}$

$\begin{array}{ll}\text { Other variables } & 41\end{array}$

$\begin{array}{ll}\text { Three-Month Follow-up Sample } & 46\end{array}$

Follow-up effects $\quad 46$

$\begin{array}{ll}\text { Correlations between change scores } & 47\end{array}$

$\begin{array}{ll}\text { Practice effects } & 48\end{array}$

Other variables $\quad 49$

Thematic Analysis of Supportive Activities and Barriers to Practice $\quad 52$

Factors that support practice $\quad 52$

Barriers to practice $\quad 54$

$\begin{array}{ll}\text { Discussion } & 57\end{array}$ 
Changes in outcome measures following course participation

Practice effects on changes in symptoms of burnout and selfcompassion 


\section{List of Tables}

Table 1. Descriptive Statistics for the 82 Study Participants

Table 2. Pre- and Post-Intervention Mean Scores for the Main Variables

Table 3. Correlations between the Main Variables at Pre- and Post-Intervention

Table 4. Correlations between Pre- and Post-Interventions Change Scores for the Main Variables

Table 5. Effect of Practice on the Pre- and Post-Intervention Change Scores for the Main Variables

Table 6. Standardized Regression Coefficients (for the Quadratic term in Parentheses) for Regressions of Levels on Practice and Pre- and PostIntervention Change Scores for Three of the Main Variables

Table 7. Pre- and Post-Intervention Mean Scores for the Other Variables

Table 8. Correlations between Pre- and Post-Intervention Change Scores for All Variables

Table 9. Effect of Practice on the Pre- and Post-Intervention Change Scores for the Other Variables

Table 10. Standardized Regression Coefficients (for the Quadratic term in Parentheses) for Regressions of Levels on Practice and Pre- and PostIntervention Change Scores for the Four Other SCS Variables

Table 11. Pre-, Post-Intervention, and Follow-up Mean Scores for the Main Variables

Table 12. Correlations between the Follow-up Change Scores for the Main Variables 
Table 13. Pre-, Post-Intervention, and Follow-up Mean Scores for the Other Variables

Table 14. Correlations between Follow-up Change Scores for All Variables

Table 15. Frequencies of Other Practices and Activities Supporting Mindfulness Practice at Post-Course and 3-Month Follow-up

Table 16. Frequencies of Perceived Barriers Related to the Maintenance of Mindfulness Practice at Post-Course and 3-Month Follow-up 


\section{List of Figures}

Figure D1. Graph of Levels of Exhaustion, Cynicism, Self-Kindness, and Self-Judgment at Pre- and Post-Course

Figure D2. Graph of Levels of Exhaustion, Cynicism, Self-Kindness, and Self-Judgment at Pre-, Post-Course, and 3-Month Follow Up 


\section{List of Appendices}

Appendix A: Health Consent Form $\quad 84$

Appendix B: Course Registration Form $\quad 85$

Consent to Participate $\quad 86$

Consent to Use Materials in Questionnaires 87

$\begin{array}{ll}\text { Appendix C: Research Materials } & 88\end{array}$

Demographic Information $\quad 88$

Permission to Use Maslach Burnout Inventory 89

Maslach Burnout Inventory - Sample Items 90

$\begin{array}{ll}\text { Self-Compassion Scale } & 91\end{array}$

Practice Survey 93

Pre-Course Questionnaire Instructions 96

Post-Course Questionnaire Instructions 97

Follow-up Questionnaire Instructions 98

$\begin{array}{ll}\text { Appendix D: Figures } & 99\end{array}$

Figure D1: Graph of Levels of Exhaustion, Cynicism, Self-Kindness, and Self-Judgment at Pre- and Post-Course 99

Figure D2: Graph of Levels of Exhaustion, Cynicism, Self-Kindness, and Self-Judgment at Pre-, Post-Course, and 3-Month Follow Up 100 


\section{List of Abbreviations}

BDI: Beck Depression Inventory

CES-D: Center for Epidemiologic Studies Depression Scale

DAS: Dysfunctional Attitudes Scale

FFMQ: Five Facet Mindfulness Questionnaire

HRQOL: Health-Related Quality of Life

IRI: Interpersonal Reactivity Index.

MAAS: Mindful Attention Awareness Scale

MBI: Maslach Burnout Inventory

MBI-GS: Maslach Burnout Inventory-General Survey

MBSM: Mindfulness-Based Symptom Management

MBSR: Mindfulness-Based Stress Reduction

POMS: Profile of Mood States

PSS: Perceived Stress Scale

RSQ: Response Style Questionnaire

SCS: Self-Compassion Scale

SMBQ: Shirom-Melamed Burnout Questionnaire

SSI: Symptoms of Stress Inventory

STAI: Spielberger State-Trait Anxiety Inventory 


\section{Mindfulness-Based Symptom Management and the Treatment of Burnout}

This research examines the effects of an 8-week mindfulness-based intervention on symptoms of burnout. Very few studies to date have explored the impact of this type of treatment specifically for the treatment of burnout (e.g., Cohen-Katz, Wiley, Capuano, Baker, \& Shapiro, 2005); however the existing literature suggests it may be effective for this purpose. The first objective of this study is to examine changes in symptoms of burnout following course participation. The Maslach Burnout Inventory-General Survey (MBI-GS; Schaufeli, Leiter, Maslach, \& Jackson, 1986) was chosen to assess symptoms of burnout given that it is currently considered the standard in burnout assessment. Results of the present study focus on emotional exhaustion, one of the three burnout subscales, because it is commonly viewed by researchers as the core construct of burnout (Shirom, 2003) and is considered for the present research as most likely to be amenable to treatment in the context of a mindfulness-based intervention by teaching participants self-regulation strategies to increase awareness of stress reactivity and its deleterious consequences for physical health and mental well-being.

The role of self-compassion in relation to course outcomes is also explored in the current study. Recent research has proposed that the measurement of self-compassion is more effective than the measurement of mindfulness for predicting symptom severity and quality of life for people suffering with psychological distress (Van Dam, Sheppard, Forsyth, \& Earleywine, 2011). Following from these findings, the second purpose of this study is to examine whether changes in self-compassion following course participation are related to symptom improvement over time. The Self-Compassion Scale (SCS; Neff, 2003) was chosen as an outcome measure for the current study as it has good 
psychometric properties and is generally accepted as the best available measure of selfcompassion.

The third purpose of this study is to examine the effects of mindfulness practice with respect to changes in self-compassion and symptoms of burnout. The role of practice in the context of a mindfulness-based intervention remains unclear (Vettese, Toneatto, Stea, Nguyen, \& Wang, 2009). A practice survey was developed for the present study to measure the frequency and duration of mindfulness practice. Given the exploratory nature of the current research, the survey included two open-ended questions to complement the quantitative findings on supports and barriers to maintaining practice. The examination of mindfulness practice as a mechanism of change in the treatment of symptoms of burnout represents a unique contribution to the mindfulness literature.

\section{Burnout}

Burnout is characterized by three interrelated dimensions: emotional and physical exhaustion; cynicism, which is experienced as interpersonal detachment or disengagement from work; and a reduced sense of professional efficacy. Its research origins in psychology followed from observational data of actual workplace experiences. However, this "bottom-up" approach to understanding the psychological underpinnings of burnout was criticized as being non-scholarly (Maslach, Schaufeli, \& Leiter, 2001). The subsequent development of psychological models to describe the phenomenon of burnout, along with extensive supporting empirical research, helped to legitimize the study of burnout as a unique psychological process arising primarily in reaction to chronic job stressors and related interpersonal conflict. 
The concept was first operationalized with the development of the Maslach Burnout Inventory (MBI; Maslach \& Jackson, 1981). Burnout is primarily characterized by exhaustion, which affects emotional regulation, physical resilience, and cognitive functioning. According to Leiter (2008), the primary feature of burnout is profound emotional, physical, and mental exhaustion, including cognitive fatigue, which results in poor attention and impaired concentration. Cognitive fatigue, also called cognitive weariness, is not included in the measurement of burnout using the MBI, but is one of three subscales (along with physical fatigue and emotional exhaustion) in the ShiromMelamed Burnout Questionnaire (SMBQ; Shirom \& Melamed, 2006). This scale is considered especially important for use with clinical populations seeking treatment for stress-related exhaustion (Lundgren-Nilsson, Jonsdottir, Pallant, \& Ahlborg, 2012). Examples of items measuring cognitive weariness using the SMBQ include "I have difficulty thinking about complex things" and "I feel I am not thinking clearly". As emotional exhaustion, physical fatigue, and cognitive weariness worsen over time, disengagement emerges, likely as a means of protecting existing resources.

Disengagement from work and subsequent feelings of cynicism towards work and others can also later contribute to a reduced sense of professional efficacy. Together, these three factors are characteristic of the burnout syndrome (Freudenburger, 1974).

Several models have been considered as accounts for the development of burnout. The Job Demand-Control Model (Karasek, 1979) proposes that the interaction between the demands of work, perceived control, and the presence of interpersonal conflict creates the conditions for burnout to occur. In addition, specific job-person characteristics (e.g., perceptions of fairness) have been examined as causal precursors to burnout (Maslach \& 
Leiter, 2008). Work environments that are highly demanding, with little control over the pace of work, few opportunities for providing input into the decision-making process, and limited social or organizational support are characteristics that have been identified as significant contributing factors to the development of burnout (ter Doest \& de Jonge, 2006). The Conservation of Resources Model (Hobfoll, 1989) suggests that these types of work environments contribute to the depletion of energetic resources and can lead to profound emotional and physical exhaustion, the primary symptom of burnout.

Leiter's (2008) two-process account of burnout includes insights from both of these models to provide an explanation of how burnout develops over time. First, an imbalance between demands and available resources leads to chronic exhaustion, the primary component of burnout. Next, an increasing awareness of the incongruence between individual and organizational values is the second major factor identified in the development of burnout. Theory development on the two-process model of burnout included a structural equation analysis which demonstrated that values incongruence has direct and indirect implications for all three dimensions of burnout (Leiter, 2008). Specifically, the two-process model proposes that values congruence provides a distinct contribution towards explaining burnout beyond issues related to job demands, workload, and sense of control. From this perspective, the development of burnout results from an incongruence between external indications of success (e.g., remuneration, or other indicators of "success" such as admiration, prestige, power) and an internal sense of dissatisfaction. It can be especially likely to occur among individuals who derive a sense of purpose from their work yet find that they are no longer making a meaningful contribution (Leiter, 2008). For example, burnout is observed more commonly amongst 
employees working within an organization with a management philosophy (e.g., profit motive) that is perceived to be in conflict with one's moral values (e.g., fairness, compassion).

The structural model of burnout (Leiter, Gascón, \& Martínez-Jarreta, 2010) expands on the two-process account by providing an explanation of the relationship between exhaustion and values incongruence. Work environments are typically hierarchical in nature, and generally offer employees few opportunities for control or influence in the determination of organizational values (Leiter et al., 2010). Values congruence is therefore considered an expression of employee confidence in organizational values which are expressed primarily through effective supervision and leadership. As described by Maslach and Leiter (2008), burnout arises when one's attitude towards the perceived discrepancy between expectations and reality begins to interfere with everyday functioning. Considering the inherent limitations in the structure and process of modern work environments (Maslach, 2003), individual efforts to reduce the discrepancy between what is and what ought to be are not likely to be successful. When attention shifts from work involvement and effective job performance towards finding ways to reduce this dissonance, the outcome can become problematic for both the organization and its employees. The structural model of burnout identifies incongruence between personal and organizational values as a significant factor related to all three dimensions of burnout, and in particular, exhaustion. Likewise, incongruence between personal and organizational values has been demonstrated previously to impact directly on levels of individual commitment and engagement with work (Leiter, 2008). 
Accordingly, both demand/resource imbalance and values incongruence are considered parallel processes in the development of burnout.

\section{Mindfulness: Definition and Efficacy}

Mindfulness has become a key topic of interest for psychological researchers and there have been a number of scales developed purporting to measure it. Mindfulness has been defined as a skill (Kentucky Inventory of Mindfulness Skills; Baer, Smith, \& Allen, 2004), a cognitive process (Mindfulness Process Questionnaire; Erisman \& Roemer, 2011), a dispositional attribute of both meditators (Toronto Mindfulness Scale; Bishop et al., 2003) and non-meditators (Mindful Attention Awareness Scale or MAAS; Brown \& Ryan, 2003), a specific therapeutic outcome (Cognitive and Affective Mindfulness ScaleRevised; Feldman et al., 2007), and as a multi-faceted construct identified through a factor analysis of previously developed mindfulness scales (Five Facet Mindfulness Questionnaire or FFMQ; Baer et al., 2006). Some researchers have argued that none of the existing scales for measuring mindfulness are adequate, although they may be measuring an altogether different and potentially important factor associated with overall psychological health and well-being. For example, Rosch (2008) considers mindfulness as defined in the psychological literature to represent a construct closer to relative sanity, or reasonableness.

Various psychological definitions of mindfulness generally include three basic characteristics. First is attention, which is the central concept of mindfulness as defined in the literature and represents the activity of mindfulness practices. Mindful attention includes physical (e.g., breathing), emotional (i.e., ability to self-regulate) and cognitive (i.e., attending and switching) processes. Next is awareness, or the intentional 
component of attention. This refers to paying attention with the intention of increasing present-focused awareness. The third component of mindfulness is acceptance, or the attitudinal component of attention, usually described as "non-judgmental" attention (Shapiro, Carlson, Astin, \& Freedman, 2006). Jha, Stanley, Kiyonaga, Wong, \& Gefland (2010) define mindfulness as "a mental mode characterized by full attention to presentmoment experience without judgment, elaboration, or emotional reactivity" (p. 54). This definition of mindfulness reflects the idea that attention represents the core of mindfulness as a psychological process.

Notwithstanding the many problems associated with defining and measuring mindfulness as a psychological construct, interest in mindfulness both within and outside psychology continues to grow. A recently proposed operational definition of mindfulness as the self-regulation of attention towards internal and external events with an attitude of non-judgmental awareness (Bishop et al., 2004) is consistent with the concept of mindfulness as a skill. There is a growing body of research evidence (e.g., Davidson et al., 2003; Goldin \& Gross, 2010) suggesting that qualities of consciousness such as mindfulness, compassion, and emotional regulation can be cultivated through systematic meditation practice (Hall, 2010). Hence, it is this definition that the current study adopts as a framework for understanding mindfulness, that is, as a cognitive skill that can be developed through the use of formal and informal mindfulness practices.

Mindfulness as a skill is defined in the context of an 8-week mindfulness-based intervention as paying attention in a particular way - with intentional and non-judgmental awareness - and is developed through attention training in both formal and informal mindfulness practices (Kabat-Zinn, 1990). Formal mindfulness practices are structured 
activities practiced for a specific length of time with the goal of gradually increasing the threshold for sustained attention. In general, formal meditation practices are considered more difficult to develop and are typically established with the use of aids (e.g., audio meditations intended for daily practice, or daily silent meditation using a signal or a bell to indicate the beginning and end of the session). Examples of formal mindfulness practices include sitting meditation, walking meditation, body scan, and yoga.

Informal mindfulness practices are typically shorter in duration and are incorporated into everyday activities with the goal of re-orienting towards presentfocused awareness. Examples of informal mindfulness practice include attending to one's breathing for brief moments throughout the day (for example, when transitioning from one activity to another) or the practice of "just noticing" thoughts and emotions as they arise with an attitude of non-judgment. The daily practice of both formal and informal activities, assigned as homework which becomes more time-intensive as the course progresses, is commonly considered by researchers and practitioners as necessary for successful participation in mindfulness-based interventions and essential for teachers and students alike to enable the acquisition of mindfulness as a skill for symptom management (Lykins \& Baer, 2008).

Chiesa, Calati, and Serretti (2011) conducted a systematic review of neuropsychological findings on the effects of mindfulness meditation practices (MMPs) on measures of cognitive functions with an emphasis on attention, memory, and executive functions. Twenty-three studies were included in the final analyses; 15 were controlled or randomized controlled studies and 8 were case-control studies. Early phases of mindfulness training (i.e., during course participation) were associated with 
significant improvements in focused attention, namely, selective and executive attention. Later phases (i.e., evaluated during follow-up phases) were associated with improvements in unfocused sustained attention. MMPs were also associated with the capacity to inhibit cognitive prepotent responses (Heeren, Van Broeck, \& Philippot, 2009). Learning to pay attention mindfully is thought to enable the recognition of habitual ways of reacting to stressful events and also to discern where and when we have a choice in how to respond. As such, the skill of mindfulness is described as the practice of learning to improve one's ability to respond "skilfully" rather than react "mindlessly" to events both internal (thoughts, emotions, and body sensations) and external (environmental stressors).

\section{Mindfulness-Based Interventions as Treatment for Burnout}

Applied research on interventions for burnout tend to focus on two areas: individualized solutions applied to a particular situation (i.e., removing the individual from the workplace for a period of time) or personality-oriented approaches (e.g., educational interventions to help employees develop more effective coping skills, or teambuilding exercises to promote interpersonal and social skills). Research on the effectiveness of these types of interventions is mixed, especially with respect to changes in cynicism and professional efficacy (Maslach et al., 2001). Nonetheless, research has demonstrated that systemic (i.e., situational and organizational) factors are frequently identified as precursors to employee burnout (Maslach et al., 2001). Given that organizational dysfunction is generally not considered easily amenable to change, the treatment of burnout remains largely focused on the individual, even when a toxic work environment can be clearly identified as the primary cause of distress. 
Leiter and Maslach (2000) recommend a combined managerial and educational approach to the treatment of burnout at both the individual and organizational level with a dual focus on building engagement between managers and employees, and promoting engagement with work. Leiter (2008) further suggests that interventions designed to foster employee engagement through learning how to adopt a different stance towards work and the organization in conformity with shared values will lead to improvements in symptoms of burnout. However the likelihood of an organization investing scarce resources into the prevention of burnout remains debatable, especially when a successful intervention outcome would be difficult to predict.

Recent research suggests that mindfulness-based interventions can be effective for the treatment of symptoms of burnout (Cohen-Katz et al., 2005). Shapiro, Brown, and Biegel (2007) discussed how mindfulness-based interventions can target symptoms of burnout by teaching participants how to relate differently towards themselves and their work and re-engage mindfully with the work environment. As previously stated, the primary symptom of burnout is exhaustion, including cognitive fatigue, which results in cognitive deficits involving attention and ability to concentrate (Leiter, 2008). To address these symptoms directly, mindfulness practices are primarily focused during the early stages of training on the development of attention regulation skills (Chiesa et al., 2011). In an fMRI study on the effects of mindfulness on emotion regulation for social anxiety disorder, Goldin and Gross (2010) found evidence of "MBSR-related changes in attention processes that may modify habitual reactivity in the context of negative selfbeliefs" (p. 89), lending further support towards the potential effects of attentional training for promoting cognitive change and symptom improvement. 
This conceptualization of early mindfulness training as attentional training is consistent with Bishop et al.'s (2004) two-component definition of mindfulness: first, the present-focused regulation of attention and, second, the subsequent development of an attitude of non-judgmental acceptance towards both internal and external experiences rather than reacting with distress or avoidance (Erisman \& Roemer, 2011). It has been suggested that the practice of systematically training attention towards identifying the onset of automatic stress reactions in the body will, over time, result in an increased ability to approach chronic work stressors as manageable, however unpleasant the experience may be at the time, before these stressors become overwhelming and interfere with adaptive functioning.

Symptoms of burnout are presented at the outset of a mindfulness-based intervention as stress responses that have become dysregulated due to chronic stress exposure. The concept of allostasis (McEwen \& Lasley, 2002) is especially relevant in the context of a burnout intervention. Allostasis is the active responding of biological mediators that maintain a state of equilibrium, or homeostasis, within the body. Allostatic load refers to signs of wear and tear on the body due to the overuse of allostasis, resulting in observable phenomena such as irritability, exhaustion, or emotional dysregulation. The result of allostatic load is the dysregulation due to overuse of the mediators which have been active in maintaining allostasis. In other words, the same systems that are designed to regulate our reactivity to acute stressors become dysregulated when exposed to chronic stressors, and the system becomes overloaded. Likewise, the primary burnout symptoms of exhaustion, cynicism, and reduced professional efficacy are described to intervention participants as physical and 
psychological manifestations of chronic stress exposure. The mindfulness-based approach to changing one's relationship ("stance" or attitude) towards thoughts and emotions is adapted to target these symptoms of work-related stress and focus on how to respond more skilfully (i.e., paying attention, considering options, and responding "mindfully" rather than with habitual, automatic or so-called "mindless" reactivity associated with stress) when these situations arise. Mindfulness training is grounded in the skill of bodily awareness of sensations occurring in the body as the stressful incident unfolds. This enables a measured, "mindful" response to perceived threat rather than the event eliciting a stress reaction, which exacerbates burnout symptoms.

\section{Rationale for the Current Study}

One focus of the current work is to examine the role of mindfulness practice as taught during an 8-week mindfulness-based intervention in alleviating burnout symptoms based on the premise that exposure to chronic work stress leads to chronic exhaustion, the primary symptom of burnout. Mindfulness practices in this context are thought to promote recovery from burnout by deliberately training attention towards the early onset of stress reactions, and by introducing mindfulness skills that can help prevent the escalation of burnout symptoms. As well, the current study will examine the effect of practice on the maintenance of positive outcomes at a 3-month follow-up. Finally, another important aspect of the current study is to explore the utility of measuring selfcompassion, rather than obtaining explicit measures of mindfulness, as there is some research to suggest that self-compassion is a more efficacious predictor of wellness outcomes than existing measures of mindfulness. Some results pertaining to these issues that have been reported recently by other researchers will now be reviewed. 
Examining the effects of mindfulness practice. The long-term practice of mindfulness meditation has been associated with improvements in self-regulation and overall well-being (Davidson et al., 2003; Lykins \& Baer, 2009). Yet in the context of mindfulness-based interventions, the relationship between mindfulness practice and program outcomes has not yet been established empirically (Vettese et al., 2009) despite consensus among practitioners and researchers alike that regular practice is necessary for achieving clinically relevant outcomes.

One key study that is related to this issue was performed by Ramel, Goldin, Carmona, and McQuaid (2004) who examined time spent practicing during an 8-week Mindfulness-Based Stress Reduction (MBSR) course for participants with a current or lifetime diagnosis of a mood disorder $(n=23)$. These researchers found that reductions in mood disturbances and dysfunctional attitudes were related to changes in rumination, and that these changes in rumination were associated with the amount of meditation practice reported. Paired $t$-tests were first conducted comparing intake and outcome measures that included the Beck Depression Inventory (BDI), the Spielberger State-Trait Anxiety Inventory (STAI), the Dysfunctional Attitudes Scale (DAS), and the Response Style Questionnaire (RSQ) that assessed coping styles. Overall, changes in all of the measures were observed except for state anxiety and perfectionism as measured by the DAS. However, no significant changes were present after controlling for changes in rumination tendencies as measured by the RSQ (where rumination is a form of maladaptive self-focused attention significantly correlated with depressed mood; NolenHoeksema, Wisco, \& Lyubomirsky, 2008). 
Hierarchical linear regression analyses were then performed to test if the average weekly amount of meditation practice reported at course completion predicted any of these outcome measures (with values at intake controlled for). Amount of meditation practice was found to significantly predict a decreased tendency to ruminate when controlling for both intake rumination and changes in depression and anxiety from pre- to post-course. However, amount of meditation practice did not predict changes in depression, anxiety, or dysfunctional attitudes. Hence, these researchers concluded that reductions in affective disturbance and dysfunctional attitudes were primarily related to changes in rumination associated with increased meditation practice.

In another key study, Carmody and Baer (2008) examined the relationship between home practice during an 8-week MBSR intervention program $(n=174)$ and outcome measures that included the Perceived Stress Scale (PSS; which assesses the degree of perceived stress experienced over the past month with respect to events described as unpredictable, uncontrollable, or overwhelming), self-reported mindfulness using the FFMQ (Baer et al., 2006), medical/psychological symptom severity, and psychological well-being. Estimates of daily home practice (minutes per day) of both formal practices (body scan, meditation, and yoga) and informal practices (mindfulness in everyday life) were provided by participants. To minimize the effects of outliers and normalize distribution of practice times, reported practice times were coded on a $0-10$ scale rather than using actual practice minutes reported. Of their initial sample, $69.5 \%$ of participants $(n=121)$ provided practice data therefore only these participants were included in the effects of practice analyses. 
Overall, participants reported an increase in mindfulness and well-being at postcourse, as well as decreases in perceived stress and medical/psychological symptom severity. Time spent engaging in formal practice was significantly related to increased mindfulness and well-being, and decreased symptom severity (as measured by change scores). Total informal time spent practicing was not shown to be correlated with changes in any outcome variables. A subsequent mediation analysis used the amount of change in mindfulness from pre- to post-intervention as a mediating variable (which was determined by summing change scores for certain facets of mindfulness, selecting only those subscales from the five-factor FFMQ that were significantly correlated with practice time). The outcome variables for each of three mediation analyses were pre-post change scores for psychological symptoms, perceived stress, and psychological wellbeing with the predictors being formal practice time. Both the relationships between formal mindfulness practice and psychological symptoms and between formal mindfulness practice and perceived stress were found to be completely mediated by selfreported increases in mindfulness. On the other hand, the relationship between formal mindfulness practice and psychological well-being was found to be only partially mediated by increased mindfulness, suggesting that other factors not included in the analyses were likely also important for explaining increased well-being following course participation.

Follow-up effects and mindfulness practice. Several researchers (Manzaneque et al., 2010; Shapiro et al., 2005) have recommended the inclusion of a follow-up measure for future studies on mindfulness intervention effects to better understand whether, and if so, how these programs purportedly work, and whether observed changes 
from pre- to post-course are lasting over time or an artifact of other unspecified factors, such as student-teacher interaction and a supportive group environment. In this vein, Grossman et al. (2010) conducted a randomized, controlled trial $(n=150)$ examining the effects of an 8-week mindfulness-based intervention for patients with multiple sclerosis (MS). Outcome assessments included the Health-Related Quality of Life scale (HRQOL; which was measured using two inventories, one for patients with chronic disorders and the other measure designed specifically for patients with MS), symptoms of depression measured using the Center for Epidemiologic Studies Depression Scale (CES-D), anxiety measured using the STAI, and fatigue measured with the Modified Fatigue Impact Scale. Their results demonstrated that the amount of practice was significantly related to improved HRQOL and reduced depression, anxiety, and fatigue at post-intervention. Furthermore, these benefits remained significant at a 6-month follow-up. Interestingly, that study reported some decline in HRQOL at follow-up, and as a result these researchers suggested that, for these types of interventions, some reinforcement (e.g., practice sessions) may be required to help remind patients of the benefits associated with regular practice. Further supporting evidence of the relationship between practice and follow-up outcomes can be found in a recent examination of the effects of an 8-week mindfulness-based intervention on attentional processing that showed that the benefits associated with mindfulness meditation were lost after six months of discontinued practice (Vago \& Nakamura, 2011). Given these concerns, both outcome and adherence to practice data collected after a 3-month follow-up period will be examined in the current study. Additionally, an exploratory qualitative analysis of supports and barriers 
to practice is included in the present study. Findings related to these data will represent an important extension of the existing mindfulness literature.

Mindfulness and self-compassion. Birnie, Speca, and Carlson (2010) examined the impact of participation by a community sample in an 8-week mindfulness-based (MBSR) program ( $n=104)$ on self-compassion as measured by the SCS (Neff, 2003), empathy as measured by the Interpersonal Reactivity Index (IRI), mindfulness as measured by the MAAS (Brown \& Ryan, 2003), and symptoms of stress and mood disturbance as measured by the Symptoms of Stress Inventory (SSI) and the Profile of Mood States (POMS). The use of SCS as an outcome measure is particularly relevant for the current study. Neff (2003) has suggested that the presence of mindfulness is a necessary prerequisite for the development of self-compassion. However, few studies have since examined the impact of mindfulness training on the cultivation of selfcompassion, although some researchers have found that self-compassion increases significantly following course participation (Shapiro, Astin, Bishop, \& Cordova, 2005; Shapiro et al., 2007). Importantly, self-compassion has recently been identified as being better than measures of mindfulness for predicting symptom severity and quality of life for people suffering from anxiety and depression (Van Dam et al., 2011). These authors also suggested that given the inherent limitations associated with the validity of the selfreport of meta-conscious mindfulness states, self-compassion measures might be better predictors to use than existing mindfulness measures with respect to the effects of mindfulness-based interventions.

In Birnie et al. (2010), the post-course questionnaire response rate (49\%) resulted in the subsequent analyses being conducted on a reduced sample $(n=51)$ where, in 
addition, the analysis involving self-compassion had to be conducted on an even smaller sample size $(n=41)$ due to incomplete questionnaire packages. Pre- to post-course changes were observed for all of the aforementioned outcome variables. At pre-course, overall levels of both self-compassion and mindfulness were negatively correlated with both mood disturbance and symptoms of stress, but not with each other. At post-course, correlations between total change scores indicated that changes in both self-compassion and mindfulness were negatively correlated with changes in mood disturbance and symptoms of stress, indicating that participants who reported an increase in either selfcompassion or mindfulness scores were also likely to report decreases in mood disturbances and symptoms of stress. Interestingly, although self-compassion and mindfulness were not significantly correlated at pre-course, they were at post-course. The fact that change scores for these two variables were correlated prompted these researchers to conclude that increases in mindfulness might be a pre-condition for increases in self-compassion. Such findings have motivated the use of the SCS as a means through which to index mindfulness-based intervention effects in the current study.

\section{Some Methodological Issues}

A common challenge for psychological researchers is the recruitment of research participants appropriate to their topic of interest. The "healthy-worker effect" (Schaufeli, Bakker, Hoodguin, Schaap, \& Kladler, 2001) refers to the study of burnout with population samples of workers not suffering symptoms of burnout, or experiencing only mild or sub-clinical levels of burnout symptoms. This shortcoming has been identified as a gap in the current burnout literature (Mākikangas, Hätinen, Kinnunen, \& Pekkonen, 
2011). For the current study, a significant proportion ( $82 \%$ ) of course participants were suffering from moderate to high initial levels of exhaustion, as measured by the MBI, the primary symptom of burnout.

Further, research findings have been mixed in terms of identifying potential biomarkers of burnout. The prevailing view among researchers is that burnout is a heterogeneous construct (Thomas, 2004) and the inconsistencies in research findings may ultimately be due to the nature of burnout itself (Tops, Boksem, Wijers, van Duinen, Den Boer, Meijman, \& Korf, 2007). A recent meta-analyses (Danhof-Pont, van Veen, \& Zitman, 2011) did not find consistent evidence that biomarkers of stress (e.g., elevated cortisol levels and blood pressure, impaired immune system functioning, sleep disturbances) were associated with symptoms of burnout. The authors concluded that this is largely due to the incomparability of studies examined and suggested several remedies for future studies, including the use of well-defined patient groups given variations in the definitions and measures used to identify burnout, and the use of a longitudinal approach to the study of burnout to further examine reasons for these contradictory findings and to permit identification of causal relationships between symptoms of burnout and outcomes (Danhof-Pont et al., 2011). The present study addresses these concerns by using a psychometrically valid and reliable measure of burnout, the MBI-GS (Schaufeli, et al., 1986) with a clinical population suffering from symptoms of burnout, and includes a longitudinal design (pre-course, post-course, and 3month follow-up) to examine changes in burnout symptom severity over time.

Finally, when examining the effects of mindfulness practice on outcomes following course participation, it is important to closely monitor adherence in 
determining the effectiveness of various types of mindfulness-based interventions. Several factors can affect adherence and attrition rates for a given program. If the screening process is inadequate, then individuals enrolled in the program but not suited to it will be less likely to adhere to the program over time. Inadequate screening also predicts poorer outcomes for course participants resulting in lower attendance and adherence to daily practice homework and higher dropout rates. Dobkin, Irving, and Amar (2011) examined when participation in this type of program may be inappropriate and suggested that screening procedures assess potential course participants for psychiatric problems, addictions, and posttraumatic stress disorder. Consistent with these recommendations, enrolment in this particular clinic is restricted to those who are more likely to benefit from participation in order to minimize adherence risks associated with engaging in meditation practice. Exclusion criteria for participants in the current study include severe depression and/or anxiety not being treated by medication, substance abuse within the last six months, current or recent suicidal thoughts, psychosis, or a history of disconnecting emotionally after exposure to trauma.

\section{The Current Study}

In this study, outcomes following participation in an 8-week mindfulness-based intervention program will first be examined. Symptoms of burnout, levels of selfcompassion, and frequencies of both formal and informal at-home practice of mindfulness activities will be measured at the beginning of the course (for burnout and self-compassion only), at the end of the course, and also after a 3-month follow-up period. Given the large number of subscales associated with both the MBI and the SCS 
(as will be evident in the subsequent Method section), the main analyses will be focused on a subset of those scales.

Overview of the hypotheses. The first hypothesis is that participants will report significantly reduced symptoms of burnout and enhanced self-compassion following participation in the mindfulness-based intervention. The second hypothesis is that changes in self-compassion will be related to improvements in symptoms of burnout. The third hypothesis is that the maintenance of practice both during the course and during the 3-month follow-up will predict more successful outcomes (i.e., reduced symptoms of burnout and increased self-compassion) at post-course and follow-up, respectively. To further explore the effects of practice, a thematic analysis of participants' open-ended responses provided at post-course and 3-month follow-up with the frequency of practice data will be conducted to identify the types of practices participants found to be most useful for maintaining practice, and to identify barriers to practice that participants typically encounter following course participation.

\section{Method}

\section{Procedure}

Description of the MBSM program. The Mindfulness-Based Symptom Management (MBSM) program is an 8-week mindfulness-based intervention that has been taught at the Ottawa Mindfulness Clinic since 2003. While not a goal of the present study, exploratory research has demonstrated that participants seeking treatment for depression, anxiety, chronic pain, and general stress management reported significant positive outcomes following course participation (Nuttall, 2009). In the aforementioned study, both the overall number of symptoms endorsed and the distress associated with 
these symptoms decreased significantly following course participation. For the current study, MBSM applicants either contacted the clinic directly seeking treatment for psychological and/or physical symptoms (typically for depression, anxiety, stress management, chronic pain, or burnout) or were referred by health care professionals who determined that their clients would potentially benefit from learning mindfulness-based skills for symptom management in a structured group environment.

The MBSM curriculum follows the standardized MBSR program developed by Kabat-Zinn (1990). The structure consists of eight weekly 2-hour classes in a smallgroup format (8-12 participants per class) with an additional class providing a full day of mindfulness practice half-way through the program. In addition to weekly class time, participants are asked to dedicate approximately 30-45 minutes each day to specific formal meditation exercises and continuous informal practices. Assigned homework includes both formal (e.g., sitting meditation) and informal methods (e.g., paying conscious attention to what you are doing, thinking, and/or feeling while engaged in everyday activities) intended as practice for cultivating mindfulness in everyday life. Classroom discussions are focused on the previous week's homework and observations related to that experience, and exploring the potential outcomes of engaging in daily mindfulness practices to reinforce the intention of each activity (e.g., paying attention to stress reactivity to improve the capacity to self-regulate) as well as the importance of completing the homework practices for developing these skills. Each course is taught by two mindfulness meditation practitioners who have completed a supervised training program in delivering the MBSM curriculum at the Ottawa Mindfulness Clinic. At least one of the teachers for each group is also a registered clinical psychologist who has 
completed the MBSR professional training program at the University of Massachusetts Center for Mindfulness in Medicine, Health Care, and Society.

Overall, the pedagogical focus throughout the eight-week MBSM program is on the cultivation of mindfulness practice, which has been shown to be effective for reducing symptom severity across a variety of psychological disorders, including depression (Grossman et al., 2010; Segal et al., 2002), anxiety (Goldin \& Gross, 2010; Manzaneque et al., 2011), chronic pain management (Rosenzweig et al., 2010; Vago \& Nakamura, 2011), and for the treatment of symptoms of burnout (Cohen-Katz et al., 2005; Davis, 2011; Oken et al., 2010).

\section{Participants}

The data come from participants who took part in one of the eight-week MBSM courses held at the Ottawa Mindfulness Clinic that were taught during 2011 in May-June (35 participants) and September-October (17 participants) and also during 2012 in January-February (30 participants). For each group, pre- and post-course data collection took place at the clinic at the beginning of the first and at the end of the last classes. In addition to on-site questionnaire completion at pre- and post-course, participants were asked to complete the practice survey and send it back by mail at one week following course completion. Participants also received by email a link to the Fluid Surveys website for submitting the practice survey posted online at post-course if they preferred. Three-month follow-up questionnaires were sent and returned by mail. Overall, 27 participants from the first two sessions completed all of the measures associated with the present research. This questionnaire completion rate is comparable to other similar 
mindfulness-based intervention research using community samples which report an average completion rate of $50 \%$ (e.g., Birnie et al., 2010).

\section{Measures}

Participants provided information regarding a number of characteristics including age, gender, marital status, education level, previous meditation practice, current spiritual practice, and reason for taking the course (symptoms of depression, anxiety, burnout, stress, and/or chronic pain management). Participants also completed three scales that included the MBI-GS (Schaufeli et al., 1996), the SCS (Neff, 2003), and a practice survey created for the purposes of this study to provide a measure of the types and frequency of mindfulness practices used for symptom management during and following the 8-week MBSM program.

Maslach Burnout Inventory. The MBI was first developed by Maslach and Jackson (1981) based on extensive qualitative and quantitative research with employees in human services and health care. Three versions have been developed for assessment of specific groups (health care, education, and general use). The version used for the current study, MBI-GS (Schaufeli et al., 1996) is a 16-item measure that has been validated across a variety of professional settings including those involving police officers, physicians, attorneys, and psychologists (Maslach, Jackson, \& Leiter, 1996). Items are rated on a 7-point Likert scale from Never (0) to Every day (6) based on how people relate to their work on a continuum from engagement to burnout (Maslach et al., 1996). Three subscales have been identified for burnout: emotional exhaustion ( 5 items), depersonalization/cynicism ( 5 items), and professional efficacy ( 6 items; where lower scores on this subscale refer to lower professional efficacy). Established cutoff scores on 
each of the three subscales are representative of burnout. Internal consistencies across Dutch $(N=941)$, North American $(N=3727)$ and Finnish $(N=290)$ samples for each of the subscales ranged from .87 to .89 for emotional exhaustion, .73 to .84 for cynicism, and .76 to .84 for professional efficacy (Maslach et al., 1996). Schutte, Toppinen, Kalimo, and Schaufeli (2000) reported that among a Dutch civil service sample $(N=956)$ who provided one-year longitudinal data, the three subscales had stability coefficients of .65 (Exhaustion), .60 (Cynicism), and .67 (Professional Efficacy). Previous research findings describe the temporal development of burnout as a process from exhaustion to cynicism with diminished professional efficacy as a secondary outcome (Hayes et al., 2004; Maslach et al., 2001). Hence, the analyses performed in this thesis will focus mainly on the exhaustion and cynicism subscales of the MBI.

Self-Compassion Scale. The SCS is a 26 -item measure with six subscales representing six components of self-compassion identified during scale development and subsequent factor analysis. The six subscales of self-compassion are divided into three categories, each containing a matched positive and negative aspect of each of the three dimensions of self-compassion: self-kindness/self-judgment, common humanity/isolation, and mindfulness/over-identification. Self-kindness refers to being tolerant and understanding toward oneself rather than disapproving and judgmental (selfjudgment). Common humanity involves viewing failure and disappointment as a normal part of the human condition instead of feeling alone and inadequate (isolation). Mindfulness is defined as an open and balanced perspective towards negative events and emotions rather than becoming preoccupied and overwhelmed by them (overidentification). The internal consistency of the total scale score was reported at .92 and 
the internal consistency reliabilities of each of the subscales ranged from .75 to .81 (Neff, 2003). Items are scored on a Likert scale from Almost never (1) to Almost always (5) based on how respondents typically act towards themselves.

It should be emphasized here that, despite its label, the mindfulness subscale is not considered here as a measure of mindfulness as operationalized in the research literature. An examination of the four questions which comprise the subscale indicates that three are redundant and involve a self-reported rating of one's ability to perceiving events and emotions from a "balanced" perspective, whereas the fourth question is the only one to reflect the non-judgmental or attitudinal component of mindfulness as defined in the research literature and adopted for the current study (i.e., "When I'm feeling down I try to approach my feelings with curiosity and openness"). Hence, this subscale is generally lacking in its conceptualization of mindfulness, given that mindfulness has been operationalized as a multi-faceted construct (e.g., FFMQ, MAAS). Instead, this subscale is perhaps measuring one's capacity for emotional stability as a self-regulation strategy. Conceptually, the mindfulness subscale can be viewed in comparison to its counterpart, over-identification, which seems to represent a person's tendency towards negative emotional reactivity. The four items which comprise the over-identification subscale each describe the tendency to over-react to negative events ("I tend to obsess and fixate on everything that's wrong"; "I become consumed by feeling of inadequacy"; "I get carried away with my feelings"; "I tend to blow the incident out of proportion"). Neff (2003) reported that a two-factor model for mindfulness/over-identification fit the data well $(\mathrm{NNFI}=.94 ; \mathrm{CFI}=.96)$, lending further support to the conceptualization of the mindfulness/over-identification subscale as a measure of emotional stability/reactivity. 
Recent findings obtained by Van Dam et al. (2011) demonstrated that of all of the self-compassion subscales, self-judgment is the one most strongly related to mindfulness scores (as measured by the MAAS) and also that self-judgment is the best predictor of changes in both depressive and anxious symptom severity, as well as quality of life (to a much greater extent than mindfulness as measured by the MAAS). Hence, the analyses performed in this thesis involving the SCS will focus mainly on the self-judgment subscale and its matched component scale that measures self-kindness.

Practice survey. To measure the frequency and duration of mindfulness practice at post-course and 3-month follow-up, a weekly practice survey was created for the purposes of this study. Participants were asked to report the frequency of practice per week (times/week) for each of the following formal mindfulness practices taught during the eight-week program: sitting meditation, walking meditation, body scan, and mindful movements (e.g., yoga). Participants also reported the frequency of practice (times/week) for each of the following informal practices: mindful bells, 3-minute breathing space, walking meditation (i.e., when transitioning from one activity to another), attending to physical sensations (e.g., heart rate, breathing) when the body is reacting to stressful events, practicing non-judgmental awareness of thoughts (i.e., "just noticing" thoughts), paying attention to emotional reactions (rather than getting "carried away"), and noticing that sense experiences arise from different "platforms" (body, sensations, thoughts, or emotions).

Participants were asked to provide an estimate of the average amount of time spent in daily practice (minutes per day) for each of the formal and informal practices listed above. Participants were also asked to provide examples of other activities not 
previously listed that they engaged in during the week that support their mindfulness practice and estimated the amount of time (minutes per day) engaged in these practices. Finally, participants were asked to list any examples of barriers or obstacles to practice. These two open-ended questions were included within the practice survey in order to conduct an exploratory thematic analysis examining the types of activities that promote and interfere with the maintenance of practice. For these analyses, the qualitative responses were first reviewed to identify key words and common themes for each openended question. Participant responses reflecting these themes were then counted, and the percentages of participants endorsing these themes are reported.

\section{Results}

\section{Sample Characteristics}

Pre- and post-intervention data were available for 82 individuals who had taken the course in May-June $2011(N=35)$, September-October $2011(N=17)$, and JanuaryFebruary $2012(N=30)$. Of those, 3-month follow-up data was available for 27 individuals (16 from the May-June 2011 session and 11 from the Sept.-Oct. 2011 session). With respect to the self-description of symptoms at entry to the intervention, 14 indicated that they were depressed, 44 indicated that they had anxiety, and 30 indicated that they were burned out (with 17 reporting either nothing or other symptoms and where these numbers add up to more than 82 because some individuals reported multiple symptoms). Descriptive statistics for the full sample are provided in Table 1. 
Table 1

Descriptive Statistics for the 82 Study Participants

\begin{tabular}{|c|c|}
\hline Age $^{a}$ & $\mathrm{M}=45.7 \quad(\mathrm{SD}=10.4)$ \\
\hline Gender $^{\mathrm{a}}$ & Female $=58(72 \%)$ \\
\hline \multirow[t]{2}{*}{ Education Level ${ }^{\mathrm{a}}$} & High School (or less) $=5(6 \%)$ University/College $=35(4$ \\
\hline & Graduate School $=31(38 \%) \quad$ Post-Graduate $=10(12 \%)$ \\
\hline \multirow[t]{2}{*}{ Marital Status ${ }^{a}$} & Single $=13(6 \%)$ Married $/$ common Law $=61(75 \%)$ \\
\hline & Separated $/$ divorced $/$ widowed $=7(9 \%)$ \\
\hline Meditation Practice ${ }^{b}$ & None $=29(38 \%)$ Some $=39(51 \%) \quad$ Regular $=8(11 \%)$ \\
\hline Spiritual Practice $^{\mathrm{b}}$ & None $=35(46 \%) \quad$ Christian $=32(42 \%) \quad$ Jewish $=2(3 \%)$ \\
\hline & Buddhist $=5(6 \%)$ Other $=2(3 \%)$ \\
\hline
\end{tabular}

${ }^{a}$ One value was not provided. ${ }^{b}$ Six values were not provided.

\section{Data Screening}

Prior to conducting the statistical analyses, the data were screened using frequency distributions (histograms and boxplots) for each MBI and SCS subscale of interest in the current study at each measurement point. Each subscale appeared to be approximately normal with the exception of cynicism and over-identification, which were slightly negatively skewed at post-course. Assumptions were checked visually for 
normality using P-P plots and histograms, and verified statistically by converting the values of skewness and kurtosis to $z$-scores and comparing the absolute values to expected values for a normal distribution (Field, 2009). The data appeared to be normal at pre-course, as none of the $z$-scores exceeded 1.96 (the standard of comparison for small sample sizes). However at post-course, while the skewness and kurtosis $z$-scores for cynicism and over-identification were not significant, the three positive subscales for self-compassion (self-kindness, common humanity, and mindfulness) seem to have slightly non-normal distributions. More specifically, the $z$-scores for skewness (between -2.95 and -4.38$)$ indicate that these data are negatively skewed $(p \leq .05)$, and the $z$-scores for kurtosis were positive (between 2.29 and 5.28) indicating a large number of scores were at mid-range $(p \leq .05)$.

To confirm these findings further testing (using the K-S test) was conducted indicating that these three distributions are significantly non-normal (for self-kindness, $D[76]=0.11, p \leq .05$; for common humanity, $D[76]=0.13, p \leq .01$; for mindfulness, $D[76]=0.17, p \leq .001)$. Given that the majority of scores were centered at mid-range, it is likely that these non-normal distributions can be attributed to a few extreme scores. A visual examination was first performed using boxplots for the identification of outliers and confirmed by calculating $z$-scores and checking for values greater than 3.00 (three standard deviations from the mean). No outliers were detected. At follow-up, the normality assumption was also verified statistically by comparing skewness and kurtosis $z$-scores to expected values. The data appeared to be normal at follow-up as none of the $z$-scores exceeded 1.96 with the exception of a slightly negatively skewed $z$-score for professional efficacy $(z=-2.32)$. 
Cronbach's alphas for each subscale of the burnout and self-compassion measures used in this study were calculated. All subscales for the MBI and SCS had high reliabilities at each measurement point. For the three burnout subscales (exhaustion, cynicism, and professional efficacy) alphas were $.92, .87$, and .85 at pre-course, respectively. At post-course, alphas were $.93, .92$, and .87 respectively. At follow up, alphas were $.96, .92$, and .86 . For the six self-compassion subscales (self-kindness, selfjudgment, common humanity, isolation, mindfulness and over-identification), alphas at post-course were $.84, .79, .82, .80, .81$, and .86 , respectively. At post-course, alphas were all between .81 and .88 . At follow up, alphas were between .84 and .90 .

\section{Pre- and Post-Intervention Sample $(N=82)$}

Main variable outcomes. Changes from pre- to post-course for the two main burnout and self-compassion outcome measures of interest are presented in Table 2 (note that $\mathrm{Ns}$ less than 82 in this table indicate that data was not provided for the measures by some individuals at either pre- or post-course). These analyses serve to address the first main hypothesis predicting significantly reduced symptoms of burnout and enhanced self-compassion following course participation. A graph of these results is also included in Appendix D for levels of exhaustion, cynicism, self-kindness, and self-judgment at pre- and post-course (Figure D1). Paired dependent $t$-tests on the change scores (i.e., in terms of post-score - pre-score) in this table indicated that levels of self-reported exhaustion were significantly lower at post-intervention than pre-intervention, that cynicism levels did not change, that levels of self-kindness significantly increased, and that levels of self-judgment significantly decreased. 
Table 2

Pre- and Post-Intervention Mean Scores for the Main Variables

Scale $\quad$ Mean (Pre) $\quad$ Mean (Post) $\quad$ Change $\quad t \quad p \quad$ Cohen's $d$
$\mathrm{MBI}^{\mathrm{a}}$ :

\begin{tabular}{lcccccc} 
Exhaustion & 3.5381 & 3.1048 & -0.4333 & -3.673 & .001 & .46 \\
Cynicism & 2.7190 & 2.5825 & -0.1365 & -1.067 & .290 & .13 \\
SCS $^{\text {b }}$ & & & & & & \\
Self-kindness & 2.8042 & 3.3746 & 0.5704 & 5.553 & .001 & .66 \\
Self-judgment & 3.3775 & 2.7541 & -0.6225 & -6.953 & .001 & .83 \\
& & & & & & \\
\hline
\end{tabular}

${ }^{\mathrm{a}} N=63 \quad{ }^{\mathrm{b}} N=71$

Correlations between measures. Pearson product-moment correlations between the two main burnout and self-compassion outcome measures of interest are presented in Table 3. As indicated in this table, all of these four measures were highly correlated with each other at both pre- and post- intervention. For example, increased levels of exhaustion were related to increased levels of cynicism, decreased levels of self-kindness, and increased levels of self-judgment. 
Table 3

Correlations between the Main Variables at Pre-and Post-Intervention

Pre-Intervention:
Exhaustion
Cynicism
Self-kindness
Self-judgment

Exhaustion

Cynicism

$$
.679^{* * *}
$$

Self-kindness

$$
-.454^{* * *}
$$

$-.334^{* *}$

Self-judgment

$.569^{* * *}$

$.339^{* *}$

$-.755^{* * *}$

Post-Intervention:

\section{Exhaustion Cynicism Self-kindness Self-judgment}

Exhaustion

$\begin{array}{llll}\text { Cynicism } & .719^{* * *} & & \\ \text { Self-kindness } & -.369^{* *} & -.286^{*} & \\ \text { Self-judgment } & .530^{* * *} & .417^{* *} & -.711^{* * *}\end{array}$

${ }^{*} p<.05^{* *} p<.01^{* * *} p<.001$ (all two-tailed)

Note: $N=74$ for all pre-intervention correlations except for the Self-kindness and Selfjudgment correlation where $N=79 . N=65$ for all post-intervention correlations except for the Self-kindness and Self-judgment correlation where $N=74$. 
Correlations between change scores. Pearson product-moment correlations between the intervention change scores for the two main burnout and self-compassion outcome measures of interest are presented in Table 4. These results serve to address the second hypothesis that changes in self-compassion will be related to improvements in symptoms of burnout. As indicated in this table, changes in exhaustion were weakly related to analogous changes in cynicism and opposite changes in self-kindness (i.e., intervention-induced decreases in exhaustion were associated with increases in selfkindness). Changes in self-kindness were related to opposite changes in self-judgment (i.e., post-intervention increases in self-kindness were associated with decreases in selfjudgment). 
Table 4

Correlations between Pre-and Post-Intervention Change Scores for the Main Variables

Exhaustion Cynicism Self-kindness Self-judgment

Exhaustion

Cynicism $.228^{(*)}$

Self-kindness $\quad-.226^{(*)} \quad-.185$

Self-judgment $\quad .096 \quad .207 \quad-.477^{* * *}$

${ }^{(*)} p<.10^{* * *} \mathrm{p}<.001$ (all two-tailed)

Note: $N=62$ for all change correlations except for the Exhaustion and Cynicism correlation where $N=63$ and the Self-kindness and Self-judgment correlation where $N=$ 71.

Practice effects. For the full sample of individuals with available change scores on the two main burnout and self-compassion outcome measures of interest, mean changes scores were computed for the group of participants who reported that they did not continue to follow the mindfulness practices at home and the group who reported that they did continue to follow them. These results serve to address the third hypothesis that the maintenance of practice both during the course and during the 3-month follow-up will predict more successful outcomes (i.e., reduced symptoms of burnout and increased selfcompassion) at post-course and follow-up, respectively. As indicated in Table 5, 
according to a set of independent group $t$-tests no significant differences in change scores between the practice and no-practice groups were evident for any of the four main outcome measures (and note that, if anything, enhanced changes in both exhaustion and self-kindness actually seemed to be present for the no-practice group). 
Table 5

Effect of Practice on the Pre-and Post-Intervention Change Scores for the Main Variables

$\underline{\text { Scale }}$ $\mathrm{MBI}^{\mathrm{a}}$ :

Exhaustion

Cynicism

$\operatorname{SCS}^{\mathrm{b}}$ :

Self-kindness

Self-judgment

0.6583

$-0.5583$

$-0.6356$

0.5525

0.1058

0.384

.702

${ }^{\mathrm{a}} N=63(11-$ No and $52-$ Yes $)$

${ }^{\mathrm{b}} N=71(12-$ No and $59-$ Yes $)$
$-0.682 \quad .498$

$0.553 \quad .582$
0.321

For the group of participants who did practice, a number of separate regression analyses were performed that included as predictors both the linear and quadratic terms for self-reported frequency of practice of each of the formal and informal mindfulness activities. The frequency of practice variables were first centered (i.e., by subtracting the mean from each value) before squaring them and adding those squared variables to the regressions (a procedure which serves to reduce any non-essential multicollinearity between the linear and quadratic terms). For these analyses, the change scores for each of the exhaustion, self-kindness, and self-judgment outcome measures (for which significant changes across the intervention were observed) were used as the dependent 
variables. These regression results are presented in Table 6. The rationale for examining quadratic effects was based on the assumption that levels of practice would follow an approximately normal distribution, and that these levels could be categorized as high, moderate, and low to compare the effects of particular types of practices with outcome variables of interest. Since the effects of high and low levels of practice may be obscured when examining linear relationships, quadratic effects were included to determine whether the effects of either very frequent practice or little/no practice would have an impact on course outcomes when examined separately from the linear effects of practice on outcomes.

For both exhaustion and self-judgment, any improvements at post-intervention in comparison to pre-intervention that are related to increased frequency of practice should be reflected in negative regression coefficients for the linear term (i.e., more practice results in more negative post - pre change scores, which signal larger reductions in these outcomes at post-intervention). As evident in this table, though, a significant positive linear relation was present between increased practice and changes in exhaustion for the informal practice of attending to physical sensations. Such an effect was not as expected and occurred because post - pre exhaustion change scores became less negative as the frequency of practice of this activity increased (and, conversely, more negative as the frequency of practice of this activity decreased). On the other hand, a marginally significant negative linear relation between practice and changes in self-judgment occurred for the informal mindful bells activity. For self-kindness, improvements at postintervention in comparison to pre-intervention that are related to increased frequency of practice should be reflected in positive correlations (i.e., more practice results in more 
positive post - pre change scores, which signal larger enhancements in this outcome at post-intervention). As evident in this table, only a marginally significant positive linear relation between the informal practice of attending to emotional reactions and changes in self-kindness was present. 
Table 6

Standardized Regression Coefficients (for the Quadratic term in Parentheses) for

Regressions of Levels on Practice and Pre-and Post-Intervention Change Scores for Three of the Main Variables

Practice

Formal:

Sitting Meditation

Walking Meditation

Body Scan

Mindful Movement/Yoga

Daily Minutes

Informal:

Mindful Bells

Three-Min. Breathing

Walking Meditation

Attend Physical Sensations

Thought Awareness

Attend Emotional Reactions

Noticing Different Sense Exp.

Daily Minutes
Exhaustion $^{\mathrm{a}}$

$$
-.061(-.056)
$$$$
.120(-.156)
$$$$
-.224(.258)
$$

$.095(-.134)$

$.069(.105)$
$.025(.044)$

$.264\left(-.411^{*}\right)$

$.176(-.230)$

$-.039(.123)$

$.174(-.096)$
$-.188(-.114)$

$-.152(-.064)$

$-.225(.220)$

$.166(-.263)$

$-.047(-.145)$

(n)


Negative regression coefficients for quadratic terms indicates that change scores are more negative for both high and low practice scores whereas positive regression coefficients for quadratic terms indicates that change scores are more positive for both high and low practice scores. For example, for the formal practice of walking meditation, smaller change scores for self-kindness were associated with both low levels of practice and higher levels of practice whereas the most positive change scores (i.e., the greatest enhancements in self-kindness) were associated with intermediate levels of practice.

Other variables. Analogous results for the $\mathrm{MBI}$ professional efficacy subscale and the four remaining SCS subscales are provided in Tables 7-10. As indicated in Table 7, although no significant post-intervention effects occurred for professional efficacy, all four of the SCS variables changed significantly at post-intervention. As indicated in Table 8 , post - pre changes in exhaustion were negatively related in a significant fashion to changes in scores on the mindfulness subscale of the SCS (i.e., decreases in exhaustion were associated with increases in mindfulness and vice versa). It can also be discerned from this table that post - pre changes in cynicism were positively related to changes in isolation and over-identification and that changes in professional efficacy were positively related to changes in self-kindness and negatively related to changes in selfjudgment. For both of these MBI variables, though, it is important to keep in mind that no significant post-intervention change scores were observed (which, of course, does not mean that all the change scores for these two MBI variables were close to zero, but simply means that both positive and negative changes in these two variables tended to cancel out on average). Finally, post - pre changes in all of the SCS variables are highly inter-correlated. 
Table 7

Pre- and Post-Intervention Mean Scores for the Other Variables

\begin{tabular}{llccccc} 
Scale & Mean (Pre) & Mean (Post) & Diff & $t$ & $p$ & Cohen's $d$ \\
MBI & & & & & & \\
Prof. Efficacy & 4.5336 & 4.4452 & -.0812 & -0.926 & .358 & .12 \\
$\mathrm{SCS}^{\mathrm{b}}$ : & & & & & & \\
Common Hum. & 2.8151 & 3.2764 & .4613 & 4.475 & .001 & .53 \\
Isolation & 3.2165 & 2.7923 & -.4243 & -3.669 & .001 & .44 \\
Mindfulness & 3.1109 & 3.5211 & .4102 & 4.487 & .001 & .53 \\
Over-Identif. & 3.4824 & 2.9577 & -.5247 & -5.002 & .001 & .59 \\
& & & & & & \\
\hline
\end{tabular}

${ }^{\mathrm{a}} N=63{ }^{\mathrm{b}} N=71$ 
Table 8

Correlations between Pre-and Post-Intervention Change Scores for All Variables

\begin{tabular}{llllllllll}
$\mathrm{EX}$ & $\mathrm{CY}$ & $\mathrm{PE}$ & $\mathrm{SK}$ & $\mathrm{SJ}$ & $\mathrm{CH}$ & $\mathrm{IS}$ & $\mathrm{MF}$ & $\mathrm{OI}$ \\
\hline
\end{tabular}

EX

CY $.228^{(*)}$

PE $\quad-.005 \quad-.156$

SK $\quad-.226^{(*)}-.185 \quad .269^{*}$

SJ $\quad .096 \quad .207 \quad-.365^{* *}-. .477^{* * *}$

$\mathrm{CH} \quad-.062 \quad .108 \quad .239^{(*)} \quad .456^{* * *} \quad-.359^{* *}$

IS $\quad .045 \quad .297^{*} \quad-.216^{(*)} \quad-.371^{* *} \quad .592^{* * *} \quad-.279^{*}$

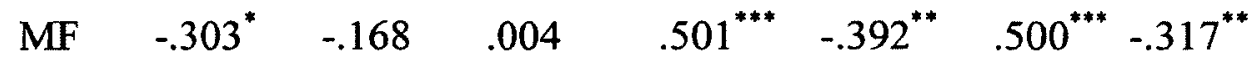

OI $\quad .238^{(*)} \quad .302^{*} \quad-.275^{*} \quad-.407^{* * *} \quad .630^{* * *}-.287^{*} \quad .640^{* * *}-.411^{* * *}$

${ }^{(*)} p<.10^{*} \mathrm{p}<.05^{* *} \mathrm{p}<.01{ }^{* * *} \mathrm{p}<.001$ (all two-tailed)

Note: $N=62$ for all change correlations involving MBI measures with SCS measures, $N=63$ for all change correlations involving MBI measures only, and $N=71$ for all change correlations involving SCS measures only. 
Table 9

Effect of Practice on the Pre-and Post-Intervention Change Scores for the Other

Variables

Scale Mean (No) Mean (Yes) Diff $p$ $\mathrm{MBI}^{\mathrm{a}}$ :

Efficacy $-0.1894$ $-0.0583$ $-0.131$ $-0.564$ .575

$\operatorname{SCS}^{\mathrm{b}}$ :

$\begin{array}{llllll}\text { Common Hum. } & 0.4896 & 0.4555 & 0.0341 & 0.123 & .902\end{array}$

$\begin{array}{llllll}\text { Isolation } & -0.6042 & -0.3877 & -0.2165 & -0.699 & .487\end{array}$

$\begin{array}{llllll}\text { Mindfulness } & 0.6250 & 0.3665 & 0.2585 & 1.061 & .293\end{array}$

$\begin{array}{llllll}\text { Over-Identif. } & -0.6771 & -0.4936 & -0.1843 & -0.653 & .516\end{array}$

${ }^{\mathrm{a}} N=63(11-$ No and $52-$ Yes $) \quad{ }^{\mathrm{b}} N=71(12-$ No and $59-$ Yes $)$

With respect to the effects of practice on changes in the four SCS variables, the two main results that are evident in Table 10 are the fact that increased practice on the formal body scan activity led to increased change scores on the mindfulness subscale of the SCS and the fact that increased change scores on the common humanity subscale of the SCS were associated with an increased number of average daily minutes of informal practice. A third significant result in that table indicates that both high and low average daily minutes of formal practice seemed to have led to lower (i.e., more negative) change scores on the isolation subscale of the SCS. 
Table 10

Standardized Regression Coefficients (for the Quadratic term in Parentheses) for

Regressions of Levels on Practice and Pre-and Post-Intervention Change Scores for the Four Other SCS Variables

Practice Common Hum, $^{\mathrm{a}} \quad$ Isolation $^{\mathrm{a}} \quad$ Mindfulness $^{\mathrm{a}}$ Over-Identif. $^{\mathrm{a}}$

Formal:

$\begin{array}{llllll}\text { Sitting Meditation } & .122(-.104) & -.023(-.112) & .187(-.138) & -.118(-.161)\end{array}$

Walking Meditation $\quad .341^{(*)}(-.270)-.340^{(*)}(.211) \quad .089(-.077) \quad-.297^{(*)}(.114)$

$\begin{array}{llllll}\text { Body Scan } & .237(.073) & .203\left(-.305^{(*)}\right) & .355^{*}(-.099) & -.048(-.098)\end{array}$

Mindful Movement/Yoga $-.089(.163) \quad .206(-.220) \quad-.317^{(*)}(.145) \quad-.040(-.020)$

Daily Minutes $\quad .145(-.095) \quad-.055\left(-.265^{*}\right) \quad .078(-.113) \quad-.224^{(*)}(.152)$

Informal:

$\begin{array}{llllll}\text { Mindful Bells } & .180(-.166) & .014(-.060) & .053(-.109) & -.183(.061)\end{array}$

Three-Min. Breathing $\quad .126(-.191) \quad .003(.066) \quad .155(-.084) \quad .024(-.036)$

$\begin{array}{lllllll}\text { Walking Meditation } & .272(-.190) & -.251(.141) & .070(-.036) & .001(-.072)\end{array}$

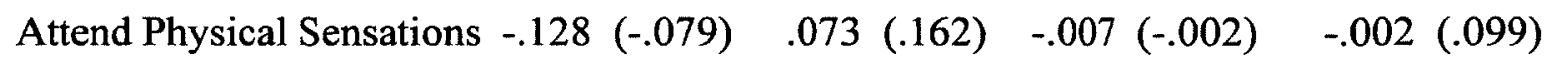

$\begin{array}{lllllll}\text { Thought Awareness } & .131 & (-.106) & -.143(.162) & .118(-.092) & -.151 & (.133)\end{array}$

Attend Emotional Reactions .116 (-..103) $\quad-.070(.206) \quad .056(-.064) \quad-.212(-.011)$

Noticing Diff. Sense Exp. $\quad .114(-.073) \quad-.219^{(*)}(-.032) .148(.144) \quad-.203 \quad(-.164)$

$\begin{array}{llllll}\text { Daily Minutes } \quad .376^{*}(-.130) & -.200(.031) & .186(.107) & -.111 & (-.019)\end{array}$

${ }^{*} p<.10^{*} \mathrm{p}<.05$ (all two-tailed)

${ }^{\mathrm{a}} N=58$ 


\section{Three-Month Follow-up Sample $(N=27)$}

Follow-up effects. Results of repeated measures ANOVAs involving the four main variables measured at pre-course, post-course, and follow-up are presented in Table 11 (note that $N$ s less than 27 in this table indicate that data was not provided for the measures by some individuals at either pre-, post-, or follow-up). A graph of these results is also included in Appendix D for levels of exhaustion, cynicism, self-kindness, and selfjudgment at pre-course, post-course, and 3-month follow-up (Figure D2). Pre- to postintervention changes were completely analogous to those obtained previously for the full sample. For each variable, changes from post-course to follow-up were tested for significance using planned pairwise comparisons. These analyses revealed that although the observed decrease in exhaustion from post-intervention to the 3-month follow-up was not significant $(t=1.553, p<.135)$, the observed decrease in cynicism from postintervention to the 3-month follow-up was significant $(t=2.113, p<.046)$. For exhaustion, while the follow-up decrease in exhaustion was not significant, the significant post-course decrease in exhaustion was maintained at follow-up. As well, although the change from post-intervention to 3-month follow-up was not significant for self-kindness $(t=0.912, p<.370)$, the significant post-course increase in self-kindness was maintained. Finally, the 3-month follow-up increase for self-judgment was significant $(t=2.0173, p<.039)$. For the latter case, note that this change represented a significant loss of the beneficial change in self-judgment following course participation (i.e., an increase back towards pre-intervention self-judgment levels). 
Table 11

Pre-, Post-Intervention, and Follow-up Mean Scores for the Main Variables

Scale Mean (Pre) Mean (Post) Mean (Follow)

$F \quad p$

$\mathrm{MBI}^{\mathrm{a}}$ :

$\begin{array}{llllll}\text { Exhaustion } & 3.626 & 3.348 & 3.130 & 3.806 & .038 \\ \text { Cynicism } & 2.835 & 2.870 & 2.452 & 2.391 & .116\end{array}$

$\operatorname{SCS}^{\mathrm{b}}:$

$\begin{array}{lrrrrr}\text { Self-kindness } & 3.046 & 3.573 & 3.435 & 6.245 & .005 \\ \text { Self-judgment } & 3.192 & 2.415 & 2.769 & 14.429 & .001\end{array}$

${ }^{\mathrm{a}} N=23 \quad{ }^{\mathrm{b}} N=26$

Correlations between change scores. Pearson product-moment correlations between the follow-up change scores for the two main burnout and self-compassion outcome measures are presented in Table 12. As indicated in this table (and as previously demonstrated for the correlations between the intervention change scores) changes in exhaustion at follow-up were marginally related to analogous changes in cynicism and opposite changes in self-kindness. Moreover, changes in self-kindness at follow-up were marginally related to opposite changes in self-judgment. 
Table 12

Correlations between the Follow-up Change Scores for the Main Variables

\begin{tabular}{llll}
\hline & Exhaustion & Cynicism & Self-kindness \\
Exhaustion & & & \\
Cynicism & $.411^{(*)}$ & & \\
Self-kindness & $-.363^{(*)}$ & -.336 & \\
Self-judgment & .342 & .092 & $-.356^{(*)}$ \\
& & & \\
\hline
\end{tabular}

${ }^{(*)} p<.10$ (two-tailed)

Note: $N=23$ for all change correlations except for the Self-kindness and Self-judgment correlation where $N=26$.

Practice effects. All 27 of the participants in the follow-up sample reported practicing the mindfulness activities at home during the 3-month follow-up period. With respect to regressions of self-reported frequency of practice for each of the formal and informal mindfulness activities during that time, and post-intervention to follow-up change scores for the four main variables, increased frequency of practice of both the informal 3-minute breathing and informal walking meditation activities were positively related to follow-up changes in self-kindness $(B=.411, p<.037$, and $B=.448, p<.025$, respectively). Hence, these two activities contributed to maintaining the previously observed post-course increase in self-kindness (as negative changes in self-kindness 
would represent decreases back to pre-intervention levels). As well, both increased practice of the informal thought awareness activity and increases in the average daily minutes of informal practice were negatively related to follow-up changes in selfjudgment $(B=-.401, p<.042$, and $B=-.448, p<.025$, respectively). Hence, these two activities were related to smaller increases in self-judgment back towards pre-intervention levels (i.e., they had a maintaining effect).

Other variables. Results of repeated measures ANOVAs involving the five other MBI and SCS variables measured at pre-course, post-course, and follow-up are given in Table 13. As for the four main variables, pre- to post-intervention changes in all of these other variables were completely analogous to those obtained for the full sample. However, none of the changes from post-course to follow-up were significant (although note that all of the scores for the SCS variables seemed to be reverting back towards preintervention levels somewhat). As indicated in Table 14, follow-up changes in all three MBI variables were inter-correlated with each other at a marginal level of significance. With respect to the SCS variables, follow-up changes in self-judgment and mindfulness were correlated with follow-up changes in a number of the other SCS variables. 
Table 13

Pre-, Post-Intervention, and Follow-up Mean Scores for the Other Variables

\begin{tabular}{lccccc} 
Scale & Mean (Pre) & Mean (Post) & Mean (Follow) & $F$ & $p$ \\
\hline MBI $^{\mathrm{a}}$ : & & & & & \\
Efficacy & 4.422 & 4.518 & 4.536 & 0.319 & .720 \\
SCS $^{\text {b: }}$ & & & & & \\
Common Hum. & 2.942 & 3.462 & 3.236 & 4.646 & .015 \\
Isolation & 3.034 & 2.423 & 2.615 & 5.029 & .010 \\
Mindfulness & 3.313 & 3.678 & 3.553 & 2.598 & .084 \\
Over-Identif. & 3.264 & 2.736 & 2.697 & 6.029 & .005 \\
& & & & & \\
\hline
\end{tabular}

${ }^{\mathrm{a}} N=23 \quad{ }^{\mathrm{b}} N=26$ 
Table 14

Correlations between Follow-up Change Scores for All Variables

\begin{tabular}{lllllllll} 
EX & $\mathrm{CY}$ & $\mathrm{PE}$ & $\mathrm{SK}$ & $\mathrm{SJ}$ & $\mathrm{CH}$ & $\mathrm{IS}$ & $\mathrm{MF}$ & OI \\
\hline
\end{tabular}

EX

CY $\quad .411^{(*)}$

$\mathrm{PE} \quad-.411^{(*)}-.365^{(*)}$

SK $\quad-.363^{(*)} \quad-.336 \quad .202$

SJ $\quad .342 \quad .092 \quad-.126 \quad-.356^{(*)}$

$\begin{array}{llllll}\mathrm{CH} & -.129 & -.101 & .211 & .265 & -.370^{(*)}\end{array}$

IS $\quad \begin{array}{llllll}.239 & -.253 & -.218 & -.062 & .695^{* * *} & -.046\end{array}$

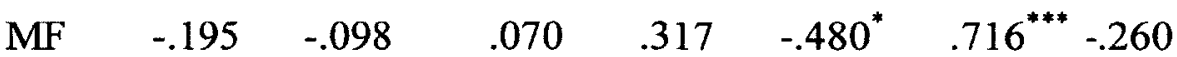

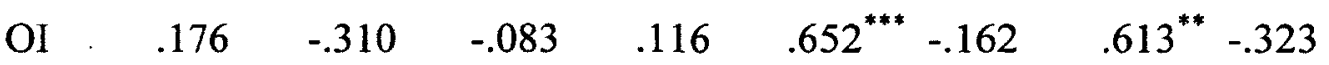

${ }^{*} p<.10^{*} \mathrm{p}<.05^{* *} \mathrm{p}<.01^{* * *} \mathrm{p}<.001$ (all two-tailed)

Note: $N=23$ for all change correlations involving MBI measures only or with SCS measures, $N=26$ for all change correlations involving SCS measures only.

Finally, with respect to the effects of the frequency of practice of each of the formal and informal mindfulness activities during the follow-up period and post-course to follow-up change scores for the five other variables, increased practice of both the informal attending to physical sensations and noticing different sensations activities were positively related to follow-up changes in mindfulness $(B=.392, p<.048$, and $B=.460$, 
$p<.018$, respectively). Hence, practice of these two activities helped to keep

mindfulness scores from dropping back to pre-intervention levels (i.e., they had a maintaining effect on mindfulness).

\section{Thematic Analysis of Supportive Activities and Barriers to Practice}

Factors that support practice. Participants provided examples at both postcourse $(N=37)$ and 3-month follow-up $(N=15)$ describing other types of mindfulness practices used regularly, and other activities that helped support practice. Although the questionnaire asked participants to provide examples of other mindfulness practices and/or activities that support their mindfulness practice, the answers provided were primarily examples of other mindfulness practices. A total of 116 responses were reported ( 83 responses at post-course and 33 responses at follow-up) which were categorized into three groups: formal practices, informal practices, and other activities supporting practice. Of these, the majority of examples provided both at post-course (59\%) and 3-month follow-up (60.5\%) were examples of other mindfulness practices followed, in addition to those practices learned during the intervention. Some other formal meditation practices that were not taught during the program were described as effective for maintaining practice $(9.6 \%$ at post-course, $9.0 \%$ at 3 -month follow-up). However, informal practices were far more frequently reported as being effective for maintaining practice both at post-course (49.4\%) and 3-month follow-up (51.4\%). These results complement the qualitative findings suggesting that practice effects are primarily associated with informal practices for these participants. Informal practices included common activities (e.g., commuting, household tasks, and spending time with loved ones) now approached as opportunities for integrating mindfulness practice into everyday 
life. These informal everyday activities used for mindfulness practice were the single most frequently cited examples of effective practice at both post-course $(26.5 \%)$ and follow-up $(30.3 \%)$. Further mindfulness practice examples provided were informal practices related to the body (e.g., breathing, "pause and reset", mindful eating), related to thoughts (observing thought patterns), and related to emotions ("slowing down" and responding, instead of reacting). Other activities (e.g., exercise, reading, seeking social support) that directly supported the maintenance of practice were also reported, with exercise the most frequently cited activity both at post-course $(19.3 \%)$ and follow-up $(27.2 \%)$. The additional practices and other activities associated with maintaining practice are summarized in Table 15 for both post-course and 3-month follow-up. 
Table 15

Frequencies of Other Practices and Activities Supporting Mindfulness Practice at Post-

Course and 3-Month Follow-up

Activities Post-Course a $^{\text {P }}$ 3-Month Follow-up

Formal practices:

Formal meditation

$8(9.6 \%)$

$3(9.0 \%)$

Informal practices:

Informal daily activities

$22(26.5 \%)$

$10(30.3 \%)$

Informal related to the body

$11(13.3 \%)$

$4(12.1 \%)$

Informal related to thoughts

$5(6.0 \%)$

$2(6.0 \%)$

Informal related to emotions

$3(3.61 \%)$

$1(3.0 \%)$

Other activities:

Exercise

$16(19.3 \%)$

$9(27.2 \%)$

Reading/education

$13(15.7 \%)$

$2(6.0 \%)$

Seeking social support

$5(6.0 \%)$

$2(6.0 \%)$

${ }^{\mathrm{a}} N=37^{\mathrm{b}} N=15$

Barriers to practice. Participants were asked to list the biggest challenges or obstacles related to mindfulness practice at post-course $(N=58)$ and 3-month follow-up $(N=21)$. In total, 102 examples of barriers to practice ( 74 provided at post-course, and 28 at 3-month follow-up) were listed which were organized into four groups: time 
management, cognitive barriers, physical barriers (e.g., fatigue, stress, pain, injury), and other barriers to practice (e.g., lack of social support). Factors related to time management (e.g., scheduling, organization, family and/or work obligations) were most commonly cited as the biggest challenge to practice at both post-course (48.7\%) and follow-up (50\%). Cognitive factors (e.g., motivation, self-discipline, remembering to practice) including negative thoughts (e.g., self-judgment, embarrassment, boredom) were also suggested as significant barriers to practice at both post-course $(31.1 \%)$ and follow-up (25\%). Perceived barriers related to the maintenance of mindfulness practice are summarized in Table 16 for both post-course and 3-month follow-up. 
Table 16

Frequencies of Perceived Barriers Related to the Maintenance of Mindfulness Practice at Post-Course and 3-Month Follow-up

Barriers

Time Management

Scheduling/organization

Other obligations (family/work)

Cognitive barriers

Motivation/discipline

Remembering to practice

Negative thinking

Physical barriers

Fatigue/Stress

Pain/Injury

Other factors

Life events interfering with practice

Lack of social support
$24(32.4 \%)$

$12(16.2 \%)$

$11(14.9 \%)$

$6(8.1 \%)$

$6(8.1 \%)$

$1(3.6 \%)$

$3(10.7 \%)$

$3(10.7 \%)$

$6(8.1 \%)$

$4(14.3 \%)$

$2(2.7 \%)$

$1(3.6 \%)$

$5(6.8 \%)$

$1(3.6 \%)$

$2(2.7 \%)$

$1(3.6 \%)$

${ }^{\mathrm{a}} N=58 \quad{ }^{\mathrm{b}} N=21$ 


\section{Discussion}

This study examined changes in symptoms of burnout and self-compassion following participation in an 8-week mindfulness-based intervention. Outcome measures were the MBI-GS (Schaufeli et al., 1996) measuring changes in symptoms of burnout, and the SCS (Neff, 2003) measuring changes in self-compassion. Due to the large number of subscales associated with both the MBI and SCS, and given recent findings on the relationship between mindfulness and self-compassion, these analyses focused mainly on changes in exhaustion, cynicism, self-kindness, and self-judgment as outcome measures. Frequencies of formal and informal at-home practice of mindfulness activities were also measured both at the end of the course and after a 3-month follow-up period, in order to determine whether any potential relationships existed between the effects of practice and outcome measures. Finally, open-ended responses on supports and barriers to practice were included to expand upon the effects of practice findings through exploratory thematic analyses.

\section{Review of the Hypotheses}

The first main hypothesis was that participants would report significantly reduced symptoms of burnout and enhanced self-compassion following participation in the mindfulness-based intervention. The second hypothesis was that changes in selfcompassion would be related to improvements in symptoms of burnout. The third hypothesis was that the maintenance of mindfulness practice both during the course and during the 3-month follow-up period would predict more successful outcomes (i.e., reduced symptoms of burnout and increased self-compassion) at post-course and followup, respectively. To further explore the effects of practice, a thematic analysis of 
participants' open-ended responses was conducted to identify the types of activities participants found to be most useful for maintaining practice, and to identify the barriers to practice that participants typically encounter following course participation.

Changes in outcome measures following course participation. The first hypothesis was that course participants would report significantly lower levels of burnout symptoms following course participation, with the analyses focused primarily on changes in exhaustion and cynicism. This hypothesis was met with respect to exhaustion, as levels of exhaustion were reported to be significantly lower at post-course. The present research also provides support for the first hypothesis with respect to observed changes in both cynicism and exhaustion at 3-month follow up, given that levels of cynicism were significantly lower at follow-up, and the observed changes in exhaustion at post-course were maintained at follow-up. Hence, these findings provide weak support, consistent with previous research, on the use of mindfulness-based interventions for the treatment of burnout. As well, scores for all SCS subscales (and, in particular, self-judgment and selfkindness) changed significantly for the better at post-course, suggesting that a major impact of the program involves learning to be more compassionate towards oneself. However given the inherent limitations of the current study, in particular its nonexperimental research design (i.e., no control group, no random assignment of participants), any conclusions pertaining to the effectiveness of the course for the treatment of burnout are not warranted. These results are thus open to many plausible alternate explanations (e.g., it could be that other factors aside from course participation, such as teacher-student interaction, exposure to a supportive group environment, or simply the passage of time, are responsible for these observed changes). 
At 3-month follow-up, the changes in exhaustion reported at post-course were maintained. These results are consistent with a similar study on the effects of MBSR on symptoms of burnout by Cohen-Katz et al. (2005) who also found significant decreases in emotional exhaustion following course participation. Also consistent with that study were the nonsignificant findings with respect to changes in both cynicism and professional efficacy at post-course. On the other hand, the significant decrease in cynicism at 3-month follow-up represents a unique result that was not observed by Cohen-Katz et al. (2005), although they did use a small sample size $(N=10)$. Likewise, self-compassion using the SCS was also measured by Cohen-Katz et al. (2005), as was mindfulness using the MAAS. As in the current study, results from that study demonstrated significant increases in mindfulness and self-compassion at post course, and these changes were also maintained at follow-up. However due to the limitations associated with the non-experimental research design, the present research could not demonstrate that changes in self-compassion are indicative of positive course outcomes. Given that the relationship between mindfulness and the development of self-compassion remains unclear, and that the present research suggests a relationship between changes in measures of burnout and self-compassion in this context, a recommendation for future mindfulness-based intervention research is to include a measure of mindfulness in addition to measures of self-compassion and burnout for examining potential intervention effects within an experimental research design.

One possible explanation for the observed lack of a significant change in cynicism at post-course may be that cynicism is an attitudinal stance that takes longer to change than other stress-related symptoms such as burnout-related exhaustion. Therefore it is 
plausible, however speculative, that changes in cynicism would only be measurable at the 3-month follow-up. There is ample environmental support for adopting a cynical outlook on life, others, and in particular towards the work environment (i.e., the perception of lazy colleagues and unfair supervisors). Shapiro et al. (2007) suggest that mindfulnessbased interventions target symptoms of burnout by teaching participants how to relate differently towards themselves and by promoting a healthy re-engagement with the work environment. Perhaps in developing coping skills during the 8-week course to better manage chronic work stress, feelings of cynicism towards the work environment may decrease as a result during the follow-up period. As proposed by Leiter et al.'s (2010) two-process model of burnout, the burnout process proceeds from exhaustion to cynicism, so it is plausible that this same pathway occurs in the treatment of burnout. Future research is suggested to further explore the current findings the relationship between changes in burnout-related exhaustion and changes in cynicism over time.

Changes in self-compassion and burnout. As just mentioned, intervention effects at post-course included significant changes in all of the SCS subscale scores, including decreased self-judgment, increased self-kindness, and increased mindfulness. Although, all of the MBI and SCS subscales were highly correlated with each other at pre- and post-intervention, changes in self-compassion were not significantly related to changes in exhaustion at either post-course or the 3-month follow-up (with the exception of a significant relation between changes in mindfulness and exhaustion at post-course and also a weak relation between changes in exhaustion and changes in self-kindness that was only marginally significant at both post-course and follow-up). Therefore, the second hypothesis of this study proposing that changes in self-compassion (and, 
especially, self-judgment) would predict burnout symptom improvement over time did not receive much support. With respect to self-judgment, it is notable that whereas selfjudgment decreased significantly at post-course, and then increased significantly at follow-up, levels of exhaustion remained low (despite the observed increase in selfjudgment at follow-up). Perhaps these findings suggest that self-judgment is not a mechanism of change in a mindfulness-based intervention for the treatment of burnout.

Such findings do not support Van Dam et al.'s (2011) suggestion that selfcompassion (and, especially, self-judgment) measures might be better predictors to use than existing mindfulness measures. However, it is also possible that the use of selfjudgment as an outcome measure is valid, but more suited to mindfulness-based interventions targeting symptoms of depression and anxiety. Van Dam et al. (2011) suggested that self-judgment may be most closely related to anxiety and depression. Hence, the characteristics of the sample may offer an explanation for these findings. Participants in the current study were more likely to be seeking treatment for symptoms of burnout (as $82 \%$ were identified at pre-course as moderate or high on the exhaustion subscale of the MBI). For interventions examining the treatment of burnout, perhaps the measurement of self-kindness (and not self-judgment) would be a more suitable predictor of post-intervention outcomes.

While it is difficult to interpret the larger meaning of change scores for individual SCS subscales as opposed to the total score on the SCS, these findings may also be suggestive of different pathways to treat symptoms of burnout. The present results suggest that changes in mindfulness and changes in self-kindness are associated with post-intervention changes in exhaustion. In particular, the fact that changes in 
mindfulness were associated with reductions in exhaustion over the course of the intervention is an interesting finding. However, as discussed in the Method section, it must be noted that the mindfulness subscale of the SCS seems more to be measuring increases in emotional stability (i.e., balance) rather than mindfulness as it is usually conceptualized. In this light, this finding suggests that increased emotional stability might represent the means by which the intervention-based reductions in exhaustion became realized in the present sample of participants.

\section{Practice effects on changes in symptoms of burnout and self-compassion.} The third hypothesis was that the maintenance of mindfulness practice both during the course and at 3-month follow-up would predict more successful outcomes (i.e., reduced symptoms of burnout and increased self-compassion) at post-course and follow-up. This hypothesis was not supported. However, the results of the exploratory thematic analyses suggest several potential directions for future research, in particular with respect to the emphasis on informal activities as effective for the maintenance of practice.

Results from Carmody and Baer (2008) will be re-examined first in order to compare them with the current results involving the effects of practice. That study examined the relationship between home practice during an 8-week MBSR intervention program and outcome measures including perceived stress, mindfulness, symptom severity, and psychological well-being. Formal practice was significantly related to increased mindfulness and well-being, and decreased symptom severity (as measured by change scores). The only formal practice effect identified in the current study was that the amount of formal body scan practice reported at post-course led to increased change scores for mindfulness. Whereas Carmody and Baer (2008) reported that total informal 
time spent practicing was not shown to be correlated with changes in any outcome variables, in the current study, practice effects were primarily associated with informal practices. This remains an interesting finding to be examined in future studies.

Overall, there were no significant differences in change scores between the practice and no-practice groups on any of the outcome measures at post-course. Pre- and post-intervention change scores for the main variables of interest suggest that outcomes were similar for both the practice and no-practice groups. In addition, there seemed to be greater changes for both exhaustion and self-kindness at post-course for the no-practice group. It could be simply that, for the no-practice group, these participants experienced positive outcomes attributable to other factors related to course participation.

It could also be the case that mindfulness-based interventions are successful in decreasing exhaustion and increasing self-kindness independent of meditation practice, such that intervention effects are experienced for all course participants as a result of other unexamined variables. Unfortunately, no comparison of the effects of practice versus no-practice could be made at 3-month follow-up because the entire 3-month follow-up group reported that they had maintained their practice. As a result, no results were available to compare with other recent findings (e.g., Vago \& Nakamura, 2011) that have suggested that the benefits associated with mindfulness meditation were lost after discontinued practice.

An interesting finding did emerge with respect to changes in cynicism at followup that suggest a possible (and entirely speculative) effect of practice that could be explored in subsequent research. While the practice group reported minimally decreased levels of cynicism at post-course, the no-practice group reported a slight increase in 
cynicism. While these differences in cynicism were not significant, the subsequent significant decrease in cynicism at 3-month follow-up for those who continued to practice was significant. Given the limitations of the current study, no firm conclusions can be made pertaining to these findings. However, they tentatively suggest that a measurable effect of practice is decreased cynicism, which could be an interesting topic for future research.

Another notable finding from the present research is that significant or marginally significant positive linear relations were present at post-course between increased practice and changes in exhaustion for the informal practices of attending to physical sensations, differentiating between sensations, and for average daily minutes reported for all informal practices. Together, these findings suggest that some people suffering from burnout may find practice detrimental, specifically with respect to their level of exhaustion. This is perhaps true, as it has been suggested that, in mindfulness-based interventions, symptoms tend to get worse before they get better as a result of increasing attention towards and cultivating an awareness of the impact of symptoms, rather than dealing with suffering using distraction or avoidance strategies (Coffey, Hartman, \& Fredrickson, 2010).

A particular strength of individuals who tend to suffer from burnout is their ability to "push through" pain, distress, or other physical and psychological challenges. While the experience of burnout seems to emerge "all of a sudden", the stresses and strains have been building in the body for years, as described by the concept of allostatic load (McEwen \& Lasley, 2002). Therefore, at the outset of a mindfulness-based intervention, burnout sufferers (who are typically dedicated and high-achieving individuals) may find 
this experience especially unsettling, and report increased levels of exhaustion as a result of the disappointment associated with facing their physical limitations. These findings suggest that certain informal practices associated with increasing awareness of physical sensations may indeed cause individuals who are suffering from burnout to experience their symptoms more intensely at the outset. This does not, however, mean that course participation is detrimental for individuals suffering from burnout, as they may be taking the first necessary steps towards preventing the re-occurrence of such symptoms.

Unlike some other studies, this one has failed to find very many significant practice effects for pre-post mindfulness intervention changes. Several factors may be responsible for these null findings. First, this is a highly self-selected sample, already in distress, and not representative of the general population. The severity of their symptoms may be greater, as would any associated changes due to intervention or practice effects, so the results here may be skewed and obscure practice effects as a result. Also, although self-reported levels of exhaustion were consistently high for these participants, the heterogeneity of the sample (e.g., presenting symptoms, reasons for taking the course, previous meditation practice, etc.) may have resulted in any potential practice effects becoming harder to detect, especially given the relatively small sample size. Finally, the symptoms of burnout were not clinically assessed for all participants, but identified through self-report. Future research may benefit from the use of a more homogeneous sample to examine potential practice effects over time.

Different research designs may prove to be more suitable for examining the relationships between practice and outcomes. Although it had been demonstrated that neurological change associated with meditation practices is measurable within an 8 -week 
mindfulness-based intervention (e.g., Davidson et al., 2003; Farb et al., 2007; Moore \& Malinowsky, 2009: Goldin \& Gross, 2010), a longitudinal design over a longer time frame may be necessary to allow for the impact of practice to take effect. An experimental research design including "practice" and "no practice" groups would be an important next step for examining the effects of mindfulness practice, an area of research which is still in the early stages of development.

Further suggestions that may help improve future mindfulness practice research include the use of a daily homework diary, extensive tracking procedures as reported in Carmody and Baer (2008), or the use of an experience sampling methodology to measure the amount of time participants spend per day in "mindful" versus "nonmindful" activities. Finally, the use of quantitative methods in conjunction with qualitative methods might help to understand what mindfulness exercises actually involve for those participants reporting program-related change.

The results of the thematic analysis conducted for this study provided extensive details on the types of practices that participants are engaged in to support their practices, and it is clear that much of the learning is taking place outside of the classroom as participants learn to incorporate mindfulness practices into everyday life. The results from the thematic analysis on barriers to practice from the current study, however preliminary, provide a unique contribution to the existing mindfulness literature since there have been very few studies (this literature review identified only one) that have explored as a primary goal the factors influencing the maintenance of practice following course participation (Langdon, Jones, Hutton, \& Holttum, 2011). 
In conclusion, it is worth noting that the experience of cultivating mindfulness practice usually involves the not-always-pleasant realization of the amount of time per day typically spent (dis)engaged with mindless activities. An acknowledgment of our habitual "mindlessness" as a first step towards learning how to practice living "mindfully" offers another plausible explanation for the lack of findings on practice effects. Although largely unexplored in the research literature to date, there may in fact be an intermediate step yet to be elucidated between learning mindfulness practices and benefitting from them. Further, these practices are considered mutually enhancing, arising from co-dependent neural activity associated with different brain regions, making it likely that wellness is an emergent property of several concurrent practices (Varela, Thompson, \& Rosch, 1993). It is therefore inherently difficult, perhaps impossible, to tease apart particular treatment effects. Although limited in its overall contribution to the nascent effects of practice literature, the current research findings at least suggest that recovery from burnout is not always a linear process and may involve some detours on the road towards well-being. This may yet prove to be a worthwhile insight for future research into how the effects of mindfulness practice manifest over time. 


\section{References}

Amrani, P. (2010). Loving-kindness: Self-compassion, burnout and empathy among therapists. Dissertation Abstracts International, 71(9). (UMI No. 3420446)

Arana, D. (2006). The practice of mindfulness meditation to alleviate the symptoms of chronic shyness and social anxiety. Dissertation Abstracts International, 67 (5-B), 2822. (UMI No. 3221757)

Arim, R., Dahinten, V. S., Marshall, S. K., \& Shapka, J. D. (2011). An examination of the reciprocal relationships between adolescents' aggressive behaviors and their perceptions of parental nurturance. Journal of Youth and Adolescence, 40, 207220.

Baer, R. A., Smith, G. T., \& Allen, K. B. (2004). Assessment of mindfulness by selfreport: The Kentucky Inventory of Mindfulness Skills. Assessment, 11, 191-206.

Baer, R. A., Smith, G. T., Hopkins, J., Krietemeyer, J., \& Toney, L. (2006). Using selfreport assessment methods to explore facets of mindfulness. Assessment, 13, 2745 .

Baron, R. M., \& Kenny, D. A. (1986). The moderator-mediator variable distinction in social psychological research: Conceptual, strategic, and statistical considerations. Journal of Personality and Social Psychology, 51(6), 1173-1182.

Birnie, K., Speca, M., \& Carlson, L. E. (2010). Exploring self-compassion and empathy in the context of mindfulness-based stress reduction (MBSR). Stress and Health, 26(5), 359-371. doi: 10.1022/smi.1305 
Bishop, S. R., Lau, M., Shapiro, S., Carlson, L., Anderson, N. D., Carmody, J., et al. (2004). Mindfulness: A proposed operational definition. Clinical Psychology: Science and Practice, 11, 230-241.

Bock, J. P. (2009). The relationship between mindfulness and burnout in psychotherapists: An exploratory study. Dissertation Abstracts International, 70(9). (UMI No. 3372772)

Brown, K.W., \& Ryan, R. M. (2003). The benefits of being present: Mindfulness and its role in psychological well-being. Journal of Personality and Social Psychology, 84, 822-848. doi: $10.1037 / 0022-3514.84 .4 .822$

Carmody, J., \& Baer, R. A. (2008). Relationships between mindfulness practice and levels of mindfulness, medical and psychological symptoms and well-being in a mindfulness-based stress reduction program. Journal of Behavioral Medicine, 31, 23-33. doi: 10.1007/s10865-007-9130-7

Carmody, J., Baer, R. A. (2009). How long does a mindfulness-based stress reduction program need to be? A review of class contact hours and effect sizes for psychological distress. Journal of Clinical Psychology, 65(6), 627-638. doi: 10.1002/jclp.20555

Carmody, J., Baer, R. A., Lykins, E. L. B., \& Olendzki, N. (2009). An empirical study of the mechanisms of mindfulness in a mindfulness-based stress reduction program. Journal of Clinical Psychology, 65(6), 613-626. doi: 10.1002/jclp.20579

Carmody, J., Reed, G., Kristeller, J., \& Phillip, M. (2008). Mindfulness, spirituality, and health-related symptoms. Journal of Psychosomatic Research, 64, 393-403. doi: 10.1016/j.jpsychores.2007.06.015 
Chiesa, A., Calati, R., \& Serretti, A. (2011). Does mindfulness training improve cognitive abilities? A systematic review of neuropsychological findings. Clinical Psychology Review, 31, 449-464. doi: 10.1016/j.cpr.2010.11.003

Coffey, K. A., Hartman, M., \& Fredrickson, B. L. (2010). Deconstructing mindfulness and constructing mental health: Understanding mindfulness and its mechanisms of action. Mindfulness, 1, 235-253. doi: 10.1007/s12671-010-0033-2

Cohen-Katz, J., Wiley, S. D., Capuano, T., Baker, D., \& Shapiro, S. (2005). The effects of mindfulness-based stress reduction on nurse stress and burnout, part II: A quantitative and qualitative study. Holistic Nursing Practice, 19(1), 26-35.

Cohn, M. A., \& Fredrickson, B. L. (2010). In search of durable positive psychology interventions: Predictors and consequences of long-term positive behaviour change. The Journal of Positive Psychology, 5(5), 355-366. doi:

$10.1080 / 17439760.2010 .508883$

Corrigan, P. W., Holmes, E. P., Luchins, D., Buican, B., Basit, A., \& Parks, J. J. (1994). Staff burnout in a psychiatric hospital: A cross-lagged panel design. Journal of Organizational Behavior, 15, 65-74.

Danhof-Pont, M. B., van Veen, T., \& Zitman, F. G. (2001). Biomarkers in burnout: A systematic review. Journal of Psychosomatic Research, 70, 505-524. doi: 10.1016/j.jpsychores.2010.10.012

Davidson, R. J., Kabat-Zinn, J., Schumacher, J. Rosenkranz, M., Muller, D., Santorelli, S. F., Urbanowski, F., Harrington, A., Bonus, K., \& Sheridan, J. F. (2003). Alterations in brain and immune function produced by mindfulness meditation. Psychosomatic Medicine, 65, 564-570. doi:10.1097/01.psy.0000077505.67574.e3 
Davis, B. G. (2011). Preventing clergy burnout: Assessing the value of a mindfulnessbased intervention as part of a holistic clergy wellness program. Dissertation Abstracts International, 72(1-B), 527. (UMI No. 3437455)

Davis, M.H. (1983). Measuring individual differences in empathy: Evidence for a multidimensional approach. Journal of Personality and Social Psychology, 44, 113-126.

De Jonge, J., Dormann, C., Janssen, P. P. M., Dollard, M. F., Landeweerd, J. A., \& Nijhuis, F. J. N. (2001). Testing reciprocal relationships between job characteristics and psychological well-being: A cross-lagged structural equation model. Journal of Occupational and Organizational Psychology, 74, 29-46.

Dobkin, P., Irving, J. A., \& Amar, S. (2011). For whom may participation in a mindfulness-based stress reduction program be contraindicated? Mindfulness. Advance online publication. doi: 10.1007/s12671-011-0079-9

Erisman, S. M., \& Roemer, L. (2011). A Preliminary investigation of the process of mindfulness. Mindfulness. Advance online publication. doi: 10.1007/s12671-0110078-x

Farb, N. A. S., Anderson, A. K., Mayberg, H., Bean, J., McKeon, D., \& Segal, Z. V. (2010). Minding one's emotions: Mindfulness training alters the neural expressions of sadness. Emotion, 10(1), 25-33. doi: 10.1037/a0017151

Farb, N. A. S., Segal, Z. V., Mayberg, H., Bean, J., McKeon, D., Fatima, Z., \& Anderson, A. K. (2007). Attending to the present: mindfulness meditation reveals distinct neural modes of self-reference. Scan, 2, 313-322. doi: 10.1093/scan/nsm/030 
Feldman, G., Hayes, A., Kumar, S., Greeson, J., \& Laurenceau, J.-P. (2007). Mindfulness and emotion regulation: The development and initial validation of the cognitive and affective mindfulness scale-revised (CAMS-R). Journal of Psychopathology and Behavioural Assessment, 29, 177-190. doi: 10.1007/s10862-006-9035-8

Field, A. (2009). Discovering statistics using SPSS ( $3^{\text {rd }}$ ed.). Thousand Oaks, CA: SAGE Publications Inc.

Frazier, P. A., Tix, A. P., \& Barron, K.E. (2004). Testing moderator and mediator effects in counseling psychology research. Journal of Counseling Psychology, 51(1), 115-134. doi: 10.1037/0022-0167.51.1.115

Freudenberger, H.J. (1974). Staff burn-out. Journal of Social Issues, 30, 159-165.

Greene, G. (1961). A Burnt-Out Case. New York, NY: The Viking Press.

Goldin, P. R., \& Gross, J. J. (2010). Effects of mindfulness-based stress reduction (MBSR) on emotion regulation in social anxiety disorder. Emotion, 10(1), 83-91. doi: $10.1037 / \mathrm{a} 0018441$

Grossman, P., Kappos, L., Gensicke, H., D’Souza, M., Mohr, D.C., Penner, I.K., \& Steiner, C. (2010). Neurology, 75, 1141-1149.

Hall, S. S. (2010). Wisdom: From Philosophy to Neuroscience. New York, NY: Vintage Books.

Hayes, A. F. (2009). Beyond Baron and Kenny: Statistical mediation analysis in the new millennium. Communication Monographs, 76(4), 408-420. doi: $10.1080 / 03637750903310360$

Hayes, S. C. (2002). Buddhism and Acceptance and Commitment Therapy. Cognitive and Behavioral Practice, 9, 58-66. 
Hayes, S. C., Bissett, R., Roget, N., Padilla, M., Kohlenberg, B. S., Fisher, G., Masuda, A., Pistorello, J., Rye, A. K., Berry, K., \& Niccolls, R. (2004). The impact of acceptance and commitment training and multicultural training on the stigmatizing attitudes and professional burnout of substance abuse counselors. Behavior Therapy, 35, 821-835.

Heeren, A., Van Broeck, N., \& Philippot, P. (2009). The effects of mindfulness on executive processes and autobiographical memory specificity. Behaviour Research and Therapy, 47, 403-409.

Hillhouse, J. J., Adler, C. M., \& Walters, D. N. (2000). A simple model of stress, burnout and symptomatology in medical residents: A longitudinal study. Psychology, Health \& Medicine, 5(1), 63-72.

Hobfoll, S. E. (1989). Conservation of resources: A new attempt at conceptualizing stress. American Psychologist, 44, 513-524.

Hölzel, B. K., Lazar, S. W., Gard, T., Schuman-Olivier, Z., Vago, D. R., \& Ott, Ulrich (2011). How does mindfulness meditation work? Proposingmechanisms of action from a conceptual and neural perspective. Perspectives on Psychological Science, 6(6), 537-559. doi: $10.1177 / 1745691611419671$

Hsieh, H.-F., \& Shannon, S. E. (2005). Three approaches to qualitative content analysis. Qualitative Health Research, 15(9), 1277-1288. doi: 10.1177/1049732305276687 Huppert, F. A., \& Johnson, D. M. (2010). A controlled trial of mindfulness training in schools: The importance of practice for an impact on well-being. The Journal of Positive Psychology, 5(4), 264-274. doi: 10.1080/17439761003794148 
Jha, A. P., Stanley, E. A., Kiyonaga, A., Wong, L., \& Gelfand, L. (2010). Examining the protective effects of mindfulness training on working memory capacity and affective experience. Emotion, 10(1), 54-64. doi: 10.1037/a0018438

Juster, R.-P., Sindi, S., Marin, M.-F., Perna, A., Hashemi, A., Pruessner, J. C., \& Lupien, S. J. (2011). A clinical allostatic load index is associated with burnout symptoms and hypocortisolemic profiles in healthy workers. Psychoneuroendocrinology, 36, 797-805. doi: 10.1016/j.psyneuen.2010.11.001

Kabat-Zinn, J. (1990). Full Catastrophe Living: Using the Wisdom of Your Body and Mind to Face Stress, Pain, and Illness. New York: Delta.

Karasek, R. A. (1979). Job demands, job decision latitude, and mental strain: Implications for job redesign. Administrative Science Quarterly, 24, 285-308.

Kenny, D. A. (1975). Cross-lagged panel correlation: A test for spuriousness. Psychological Bulletin, 82(6), 887-903.

Khalsa, D. S. (2010). Mindfulness effects on caregiver stress: Should we expect more? The Journal of Alternative and Complementary Medicine, 16(10), 1025-1026. doi: $10.1089 / \mathrm{acm} .2010 .0431$

Langdon, S., Jones, F. W., Hutton, J., \& Holttum, S. (2011). A grounded theory of mindfulness practice following mindfulness-based cognitive therapy. Mindfulness, 2, 270-281.

Langelaan, S., Bakker, A. B., Schaufeli, W. B., van Rhenen, W., \& van Doornen, L. J. P. (2007). Is burnout related to allostatic load? International Journal of Behavioral Medicine, 14(4), 213-221. doi: 10.1007/s/12671-011-00705 
Leiter, M. P. (2008). A two process model of burnout and work engagement: Distinct implications of demands and values. Supplemento A, Psicologia, 30(1), A52 A58.

Leiter, M. P., Gascón, S., \& Martínez-Jarreta, B. (2010). Making sense of work life: A Structural model of burnout. Journal of Applied Social Psychology, 40(1), 57-75.

Leiter, M. P., \& Maslach, C. (1988). The impact of interpersonal environment on burnout and organizational commitment. Journal of Organizational Behavior, 9, 297308.

Leiter M. P., \& Maslach C. (2000). Preventing burnout and building engagement: $A$ complete program for organizational renewal. San Francisco, CA: Jossey-Bass.

Lundgren-Nilsson, A., Jonsdottir, I. H., Pallant, J., \& Ahlborg, A. (2012). Internal construct validity of the Shirom-Melamed Burnout Questionnaire (SMBQ). BMC Public Health, 12(1), 1-8. doi: 10.1186/1471-2458-12-1

Lykins, E. L. B., \& Baer, R. A. (2009). Psychological functioning in a sample of long term practitioners of mindfulness meditation. Journal of Cognitive Psychotherapy: An International Quarterly, 23(3), 226-241. doi: 10.1891/08898391.23.3.226

MacKinnon, D. P., Krull, J. L., \& Lockwood, C. M. (2000). Equivalence of the meditation, confounding, and suppression effects. Prevention Science, 1, 173-181. doi: $10.1007 / \mathrm{s} 10865-007-9130-7$

Mākikangas, A., Hätinen, M., Kinnunen, U., \& Pekkonen, M. (2011). Longitudinal factor invariance of the Maslach Burnout Inventory-General Survey among employees 
with job-related psychological health problems. Stress and Health, 27, 347-352. doi:10.1002/smi.1381

Malcoun, E. (2009). Unpacking mindfulness: Psychological processes underlying the health benefits of a mindfulness-based stress reduction program. Dissertation Abstracts International, 69(1-B), 7817. (UMI No. 3338924)

Manzaneque, J. M., Vera, F. M., Ramos, N. S., Godoy, Y. A., Rodriquez, F. M., Blanca, M. J., Fernandez, A., \& Enguix, A. (2011). Psychobiological modulation in anxious and depressed patients after a mindfulness meditation programme: A pilot study. Stress and Health, 27, 216-222. doi: 10.1002/smi.1334

Martens, M. P. \& Haase, R. F. (2006). Advanced Applications of Structural Equation Modeling in Counseling Psychology Research. The Counseling Psychologist, 34(6), 878-911. doi: 10.1177/0011000005283395

Maslach, C. (2003). Job burnout: New directions in research and intervention. Current Directions in Psychological Science, 12(5), 189-192. doi: 10.1111/14678721.01258

Maslach, C., \& Jackson, S. E. (1981). The measurement of experienced burnout. Journal of Occupational Behaviour, 2, 99-113.

Maslach, C., Jackson, S. E., \& Leiter, M. P. (1996). MBI Manual ( ${ }^{\text {rd }}$ ed.). Palo Alto, CA: Consulting Psychologists Press.

Maslach, C., \& Leiter, M. P. (2008). Early predictors of job burnout and engagement. Journal of Applied Psychology, 93(3), 498-512. doi: 10.1037/0021-9010.93.3.498 Maslach, C., Schaufeli, W. B., \& Leiter, M. P. (2001). Job burnout. Annual Review of Psychology, 52, 397-422. doi: 10.1146/annurev.psych.52.1.397 
McEwen, B. \& Lasley, E.N. (2002). The End of Stress as We Know It. Washington, DC: Joseph Henry Press.

Musten, R. F., \& Monteiro, L.M. (2010). Minding the life you have. Ottawa, ON: Ottawa Mindfulness Clinic.

Michalak, J., Troje, N. F., \& Heidenreich, T. (2011). The effects of mindfulness-based cognitive therapy on depressive gait patterns. Journal of Cognitive and Behavioral Psychotherapies, 11(1), 13-27.

Moore, A., \& Malinowski, P. (2009). Meditation, mindfulness, and cognitive flexibility. Consciousness \& Cognition, 18(1), 176-186. doi: 10.1002/jclp.20776

Muller, D., Judd, C. M., \& Yzerbyt, V.Y. (2005). When moderation is mediated and mediation is moderated. Journal of Personality and Social Psychology, 89(6), 852-863. doi: $10.1037 / 0022-3514.89 .6 .852$

Neff, K. D. (2003). Development and validation of a scale to measure self compassion. Self and Identity, 2, 223-250.

Newberg, A. B., Wintering, N., Khalsa, D. S., Roggenkamp, H., \& Waldman, M.R. (2010). Meditation effects on cognitive function and cerebral blood flow in subjects with memory loss: A preliminary study. Journal of Alzheimer's Disease, 20, 517-526. doi: 10.3233/JAD-2010-1391

Nolen-Hoeksema, S., Wisco, B. E., \& Lyubomirsky, S. (2008). Rethinking rumination. Perspectives on Psychological Science, 3(5), 400-424.

Nuttall, S. (2009). Mindfulness-based symptom management: A naturalistic study of a new mindfulness-based intervention. (Unpublished undergraduate honours thesis). University of Ottawa, Canada. 
Oken, B. S., Fonareva, I., Haas, M., Wahbeh, H., Lane, J. B., Zajdel, D., \& Amen,A. (2010). Pilot controlled trial of mindfulness meditation and education for dementia caregivers. The Journal of Alternative and Complementary Medicine, 16(10), 1031-1038. doi: 10.1089/acm.2009.0733

Peeters, C., Stewart, A., Segal, R., Wouterloot, E., Scott, C.G., \& Aubry, T. (2009). Evaluation of a cancer exercise program: Patient and physician beliefs. Psycho-Oncology, 18(8), 898-902. doi: 10.1002/pon. 1406

Pines, A. M. (2002). Teacher burnout: A psychodynamic existential perspective. Teachers and Teaching: theory and practice, 8(2), 121-140. doi: $10: 1080 / 1354060022012733$

Preacher, K. J., Zyphur, M. J., \& Zhang, Z. (2010). A general multilevel SEM framework for assessing multilevel mediation. Psychological Methods, 15(3), 209-233. doi: $10.1047 / \mathrm{a} 0020141$

Ramel, W., Goldin, P. R., Carmona, P. E., \& McQuaid, J. R. (2004). The effects of mindfulness meditation on cognitive processes and affect in patients with past depression. Cognitive Therapy and Research, 28(4), 433-455.

Reynolds, J. W. (2011). Mechanisms of action in mindfulness-based stress reduction (MBSR), and specific factors mediating the reduction of anxiety. Dissertation Abstracts International, 72(2-B), 1174. (UMI No. 3437809)

Rogosa, D. (1980). A critique of cross-lagged correlation. Psychological Bulletin, 88(2), 245-258.

Rosenzweig, S., Greeson, J. M., Reibel, D. K., Green, J. S., Jasser, S. A., \& Beasley, D. (2010). Mindfulness-based stress reduction for chronic pain conditions: 
Variations in treatment outcomes and role of home meditation practice. Journal of Psychosomatic Research, 68, 29-36. doi:10.1016/j.jpsychores.2009.03.010

Ryff, C. D., \& Keyes, C. L. M. (1995). The structure of psychological well-being revisited. Journal of Personality and Social Psychology, 69, 719-727.

Schaufeli, W., Bakker, A., Hoodguin, K., Schaap, \& Kladler, A. (2001). On the clinical Validity of the Maslach Burnout Inventory and the burnout measure. Psychology and Health, 16, 565-582.

Schaufeli, W., Leiter, M. P., \& Maslach, C. (2009). Burnout: 35 years of research and practice. Career Development International, 14(3), 204-220.

Schaufeli, W., Leiter, M. P., \& Maslach, C., \& Jackson, S. E. (1996). Maslach Burnout Inventory-General Survey (MBI-GS). In Maslach, C., Jackson, S. E., \& Leiter, M. P. (Eds). MBI Manual ( $3^{\text {rd }}$ ed.). Palo Alto, CA: Consulting Psychologists Press.

Schutte, N., Toppinen, S, Kalimo, R., \& Schaufeli, W. (2000). The factorial validity and the Maslach Burnout Inventory-General Survey (MBI-GS) across occupational groups and nations. Journal of Occupational and Organizational Psychology, 73, $53-66$.

Segal, Z. V., Williams, J. M. G., \& Teasdale, J. D. (2002). Mindfulness-based cognitive therapy for depression: a new approach to preventing relapse. New York, NY: The Guilford Press.

Shapiro, S. (2009). The integration of mindfulness and psychology. Journal of Clinical Psychology, 65(6), 555-560. doi: 10.1002/jclp.20602 
Shapiro, S. L., Astin, J. A., Bishop, S. R., \& Cordova, M. (2005). Mindfulness-based stress reduction for health care professionals: Results from a randomized trial. International Journal of Stress Management, 12, 164-176.

Shapiro, S. L., Brown, K. W., \& Biegel, G. M. (2007). Teaching self-care to caregivers: Effects of mindfulness-based stress reduction on the mental health of therapists in training. Training and Education in Professional Psychology, 1(2), 105-115. doi: 10.1037/1931-3918.1.2.105

Shapiro, S. L., Brown, K. W., Thorensen, C., \& Plante, T. G. (2011). The moderation of mindfulness-based stress reduction effects by trait mindfulness: Results from a randomized controlled trial. Journal of Clinical Psychology, 67(3), 267-277. doi: 10.1002/jclp.20761

Shapiro, S. L., Carlson, L. E., Astin, J. A., \& Freedman, B. (2006). Mechanisms of mindfulness. Journal of Clinical Psychology, 62, 373-386. doi: $10.1002 /$ jclp. 20237

Shirom, A. (2003). Job-related burnout. In J. C. Quick \& L. E. Tetrick (Eds.). Handbook of occupational health psychology. (pp. 245-265). Washington, DC: American Psychological Association.

Shirom, A., \& Melamed, S. (2006). A comparison of the construct validity of two burnout measures among two groups of professionals. International Journal of Stress Management, 13(2), 176-200. doi: 10.1037/1072-5245.13.2.176

Starrin, B., Larsson, G., \& Styrborn, S. (1990). A review and critique of psychological approaches to the burn-out phenomenon. Scandinavian Journal of Caring Sciences, 4(2), 83-91. 
Taylor, C. (1991). The malaise of modernity. Concord, Ontario: House of Anansi Press Limited.

Ter Doest, L., \& De Jonge, J. (2006). Testing causal models of job characteristics and employee well-being: A replication study using cross-lagged structural equation modelling. Journal of Occupational and Organizational Psychology, 79,499-507. doi: $10.1348 / 096317905 X 55271$

Thomas, N. K. (2004). Resident burnout. Journal of the American Medical Association, 292(23), 2880-2889.

Toker, S., Shirom, A., Shapira, I., Berliner, S., \& Melamed, S. (2005). The association between burnout, depression, anxiety, and inflammation biomarkers: C-reactive protein and fibrinogen in men and women. Journal of Occupational Health Psychology, 10(4), 344-362. doi: 10.1037/1076-8998.10.4.344

Tops, M., Boksem, M. A. S., Wijers, A. A., van Duinen, H., Den Boer, J. A., Meijman, T. F., \& Korf, J.(2007). The psychobiology of burnout: Are there two different syndromes? Neuropsychobiology, 55, 143-150.

Travis, F. (2011). Mindfulness and psychologic well-being: Are they related to type of meditation practiced? The Journal of Alternative and Complementary Medicine, 17(11), 983-984. doi: 10.1089/acm.2011.0507

Vago, D. R. \& Nakamura, Y. (2011). Selective attentional bias towards pain-related threat in fibromyalgia: Preliminary evidence for effects of mindfulness meditation training. Cognitive Therapy and Research, 35, 581-594. doi: 10.1007/s10608011-9391-x 
Van Dam, N. T., Sheppard, S. C., Forsyth, J. P., \& Earleywine, M. (2011). Self compassion is a better predictor than mindfulness of symptom severity and quality of life in mixed anxiety and depression. Journal of Anxiety Disorders, 25, 123-130. doi: 10.1016/j.janxdis.2010.08.011

Varela, F. J., Thompson, E., \& Rosch, E. (1991). The embodied mind: Cognitive science and human experience. Cambridge, MA: MIT Press.

Vettese, L. C., Toneatto, T., Stea, J. N., Nguyen, L., \& Wang, J. J. (2009). Do mindfulness meditation participants do their homework? And does it make a difference? A review of the empirical evidence. Journal of Cognitive Psychotherapy: An International Quarterly, 23(3), 198-225. doi: 10.1891/08898391.23.3.198

Weber, M. (2001). The protestant ethic and the spirit of capitalism. New York, NY: Routledge.

Wenk-Sormaz, H. (2005). Meditation can reduce habitual responding. Alternative Therapies in Health and Medicine, 11, 42-58.

Williams, J. M. G. (2010). Mindfulness and Psychological Process. Emotion, 10(1), 1-7. doi: $10.1037 / \mathrm{a} 0018360$

Wright, D. (2003). Producing bad results sections. The Psychologist, 16, 646-648.

Zacher, H., \& de Lange, A. H. (2011). Relations between chronic regulatory focus and future time perspective: Results of a cross-lagged structural equation. Personality and Individual Differences, 50, 1255-1260. doi: 10.1016/j.paid.2011.02.020 
Zapf, D., Dormann, C., \& Frese, M. (1996). Longitudinal studies in organizational stress research: A review of the literature with reference to methodological issues. Journal of Occupational Health Psychology, 1(2), 145-169. 


\section{Appendix A: Health Consent Form \\ Ottawa Mindfulness Clinic Health Consent Form}

NOTE TO CLIENT: We want your informed consent for the services we are to provide. This means that we want you to understand the services we hope to provide to you, the cost involved, and what we do with the personal information we obtain about you. If you have a question about any of this, please ask.

CONSENT FOR ASSESSMENT I understand that I am inquiring into psychological services which, if appropriate, involve attendance at an 8-week mindfulness program. All information provided is maintained in confidence. A release of information will be required for any report or transmission of information I request.

LIMITS OF CONFIDENTIALITY Some occasions constitute a limit to confidentiality. Disclosure is legally/ethically required:

- When information is given by a client that indicates potential harm to self or others;

- When a search warrant or subpoena is issued to obtain client information;

- When there is a possibility that a child has been or is being abused and no report has been made to the Children's Aid Society;

- When there is a possibility that a child is witness to abuse or aggression between adults;

- When information is given about previously unreported sexual abuse by a health care professional who has been or currently is treating a client.

CONSENT FOR THE COST OF THIS INTAKE ASSESSMENT There is no charge for this intake assessment. If I wish to register for the 8-week program a non-refundable deposit of $\$ 60.00$ will be required and this amount will be deducted from the total cost of the program at the time I make payment on the remainder. Further consent to participate in the program and other payment information will be provided in the registration form.

CONSENT FOR PERSONAL INFORMATION I understand that to provide me with psychological services, the Ottawa Mindfulness Clinic will collect some personal information about me (e.g., home telephone number, address, general demographic information, insurance codes).

I understand that the Ottawa Mindfulness Clinic Privacy Policy is available to me for review if requested. The Privacy Policy concerns the collection, use and disclosure of personal information, steps taken to protect the information and my right to review my personal information. Upon review of the Privacy Policy, I will be given a chance to ask any questions I have to understand how the Privacy Policy applies to me.

I understand that, as explained in the Policies and Procedures for Personal Information, there are some rare exceptions to these commitments.

I agree to the Ottawa Mindfulness Clinic collecting, using and disclosing personal information about me as set out above and in the Ottawa Mindfulness Clinic's Privacy Policy.

SIGNATURE:

DATE:

PRINTED NAME: 
Appendix B: Course Registration Form

MINDFULNESS-BASED SYMPTOM MANAGEMENT

An eight week course in skillful living

Registration:

DAY $\square$

EVENING

Name:

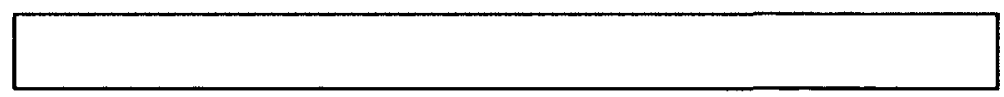

Address:

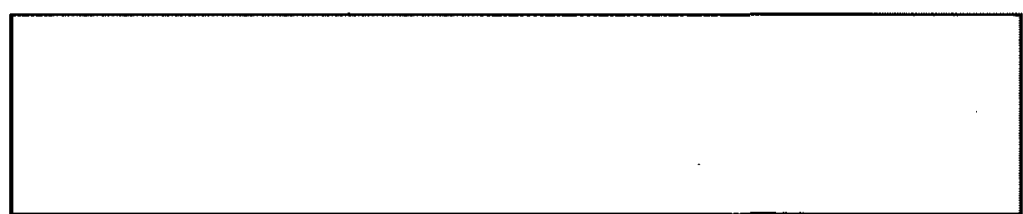

Phone (day):

Phone (eve):

Family Physician:

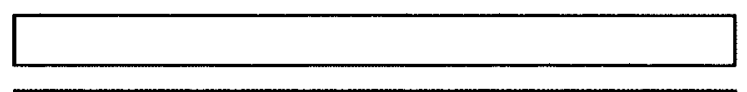

In case of emergency, please call (include number):

\section{Current Therapy}

$\square \mathrm{l}$ am not in therapy.

$\square$ I am presently working in therapy with

We meet

$\square$ Once a week

$\square$ Twice a week

Once a month 


\section{MY CONSENT TO PARTICIPATE}

Please read the following and check a box to indicate your response

This program is an eight week course comprised of learning awareness and meditation techniques, instructions and teachings on various aspects of managing my symptoms, and discussing weekly assignments. Aware that it will demand my time and resources,

$\square \mathrm{l}$ am willing to engage in this course

$\square$ I am not ready to engage in this course

This program includes many persons with varying backgrounds, strengths and difficulties. Aware that maintaining confidentiality of the information that is shared with me is crucial to encouraging feelings of openness and security,

$\square \mathrm{I}$ am committed to maintaining confidences in this course

$\square$ I am not ready to engage in this action

This program is conducted by psychologists who are required to comply with legal limits of confidentiality. Aware that disclosures of threat to myself or others, unreported physical, sexual or emotional abuse of children, unreported sexual abuse by health care professionals, and/or presentation of subpoenas or search warrants must be complied with or reported to appropriate authorities,

$\square$ I am willing to engage in this course

$\square$ I am not ready to engage in this course

$\square$ Aware of the conditions above and of the implications they address, I agree to engage in this program.

$\square$ Aware of the conditions above and of my feelings at this time, I am not ready to engage in this program.

Signature

date

Witness signature

date 


\section{CONSENT TO USE MATERIALS IN QUESTIONNAIRES}

I have been provided with questionnaires assessing various physical and emotional symptoms and understand these data will be used to evaluate the usefulness of the program and for research in effectiveness of mindfulness interventions. If I wish feedback at the end of the program and follow-up appointments, I may contact the facilitators.

If these data are used in research publications, I am assured of anonymity in the use of my responses.

Aware that the data may be beneficial to myself and will contribute to the improvement of the program over time,

$\square$ I consent to provide the information requested in the questionnaires AND (ONE of the following)

$\square$ to the use of the data to examine the effectiveness of the program and for possible publication with assurances of confidentiality of my identity

$\square$ solely for feedback (decline to have it used for research purposes)

Signature

date

Witness signature

date 
Appendix C: Research Materials

DEMOGRAPHIC INFORMATION

Name:

DOB: Month

Day

Year

Age:

Gender: $\square \mathrm{M} \quad \square \mathrm{F}$

Occupation:

Highest education level completed:

Marital Status: $\square$ single $\square$ married $\square$ common-law

$\square$ separated $\square$ divorced $\square$ widowed

Previous meditation practice: $\square$ none $\square$ some $\square$ regular practice

Current spiritual practice: $\square$ no affiliation $\square$ Christian $\square$ Jewish $\square$ Muslim $\square$ Buddhist $\square$ Hindu $\square$ other not listed:

Self-description: Please choose the description which best fits you at this time.

$\square$ Depression $\square$ Anxiety $\quad \square$ Burnout

$\square$ other (describe here): 
For use by Roy Musten only. Received from Mind Garden, Inc. on November 19, 2010

\section{mind garden www.mindgarden.com}

To whom it may concern,

This letter is to grant permission for the above named person to use the following copyright material;

Instrument: Maslach Burnout Inventory, Forms: General Survey, Human Services Survey \& Educators Survey

\section{Authors}

MBI-General Survey: Wilmar B. Schaufeli, Michael P. Leiter, Christina Maslach \& Susan E. Jackson

MBI-Human Services Survey: Christina Maslach \& Susan E. Jackson

MBI-Educators Survey: Christina Maslach, Susan E. Jackson \& Richard L. Schwab

Copyright: Copyright $(1986$ by CPP, Inc. All rights reserved in all mediums.

for his/her thesis research.

Three sample items from a single form of this instrument may be reproduced for inclusion in a proposal, thesis, or dissertation.

The entire instrument may not be included or reproduced at any time in any other published material.

Sincerely,

Robert Most

Mind Garden, Inc.

www.mindgarden.com 


\section{MBI - General Survey}

Maslach Burnout Inventory - General Survey (MBI-GS; Schaufeli, Leiter, Maslach, \& Jackson, 1986). Published by Mind Garden, Inc., www.mindgarden.com.

Please read each statement carefully and decide if you ever feel this way about your job. If you have never had this feeling, write a " 0 " (zero) in the space before the statement. If you have had this feeling, Indicate how often you feel it by writing the number (from 1 to 6) that best describes how frequently you feel that way.

$\begin{array}{ccccccc}0 & 1 & 2 & 3 & 4 & 5 & 6 \\ \text { Never } & \text { A few } & \text { Once a } & \text { A few } & \text { Once a } & \text { A few } & \text { Every day } \\ & \text { times a } & \text { month or } & \text { times a } & \text { week } & \text { times a } & \\ & \begin{array}{c}\text { year or } \\ \text { less }\end{array} & \text { less } & \text { month } & & \text { week } & \end{array}$

Sample Items:

1.

I feel I am making an effective contribution to what this organization does.

2. I have become more cynical about whether my work contributes anything.

3. I feel burned out from my work.

Copyright $\mathbb{C} 1986$ by CPP, Inc. All rights reserved in all mediums. 


\section{SELF-COMPASSION SCALE}

\section{HOW I TYPICALLY ACT TOWARDS MYSELF IN DIFFICULT TIMES}

Please read each statement carefully before answering. To the left of each item, indicate how often you behave in the stated manner, using the following scale:

Almost never

1

4

Almost always 5

1. I'm disapproving and judgmental about my own flaws and inadequacies.

2. When I'm feeling down I tend to obsess and fixate on everything that's wrong.

3. When things are going badly for me, I see the difficulties as part of life that everyone goes through.

4. When I think about my inadequacies, it tends to make me feel more separate and cut off from the rest of the world.

5. I try to be loving towards myself when I'm feeling emotional pain.

6. When I fail at something important to me I become consumed by feelings of inadequacy.

7. When I'm down and out, I remind myself that there are lots of other people in the world feeling like I am.

8. When times are really difficult, I tend to be tough on myself.

9. When something upsets me I try to keep my emotions in balance.

10. When I feel inadequate in some way, I try to remind myself that feelings of inadequacy are shared by most people.

11. I'm intolerant and impatient towards those aspects of my personality I don't like.

12. When I'm going through a very hard time, I give myself the caring and tenderness I need.

13. When I'm feeling down, I tend to feel like most other people are probably happier than I am. 


\section{HOW I TYPICALLY ACT TOWARDS MYSELF IN DIFFICULT TIMES}

Please read each statement carefully before answering. To the left of each item, indicate how often you behave in the stated manner, using the following scale:

Almost

never

1

2

Almost

always

5

14. When something painful happens I try to take a balanced view of the situation. 15. I try to see my failings as part of the human condition.

16. When I see aspects of myself that I don't like, I get down on myself.

17. When I fail at something important to me I try to keep things in perspective.

18. When I'm really struggling, I tend to feel like other people must be having an easier time of it.

19. I'm kind to myself when I'm experiencing suffering.

20. When something upsets me I get carried away with my feelings.

21 . I can be a bit cold-hearted towards myself when I'm experiencing suffering.

22. When I'm feeling down I try to approach my feelings with curiosity and openness.

23. I'm tolerant of my own flaws and inadequacies.

24. When something painful happens I tend to blow the incident out of proportion.

25. When I fail at something that's important to me, I tend to feel alone in my failure.

26. I try to be understanding and patient towards those aspects of my personality I don't like. 


\section{Practice Survey}

A survey of your weekly mindfulness practice

1. Did you continue to follow any of the mindfulness practices you learned in the program?

○ Yes

O No

2. Which formal practices did you continue to practice during this past week?

"Formal" practices are engaged in for a specific period of time, either using a meditation aid (e.g. listening to a guided meditation on cd) or on your own for a specific period of time and generally requiring the use of a signal (e.g. an alarm, timer, or bell) to indicate the end of the meditation period. These practices are called "formal" because they are typically more structured and require you to set aside a specific period of time dedicated exclusively to their practice.

$\begin{array}{llllll} & \text { Daily } & \begin{array}{l}5-6 \\ \text { times }\end{array} & \begin{array}{l}3-4 \\ \text { times }\end{array} & \begin{array}{l}1-2 \\ \text { times }\end{array} & \text { Never } \\ \begin{array}{lllll}\text { Sitting meditation (e.g. a guided meditation, or, } \\ \text { using a timer to signal the end of the }\end{array} & 0 & 0 & 0 & 0 & 0 \\ \begin{array}{l}\text { meditation period) } \\ \text { Walking meditation }\end{array} & 0 & 0 & 0 & 0 & 0 \\ \text { Body scan } & 0 & 0 & 0 & 0 & 0 \\ \text { Mindful movements/Yoga } & 0 & 0 & 0 & 0 & 0\end{array}$

3. Which informal practices did you continue to practice during this past week?

"Informal" practices are essentially 'reset' moments used throughout the day to re-orient yourself towards present-focused awareness. Informal practices are also typically shorter in duration than formal practices, and are more readily incorporated into everyday activities.

Mindful Bells

3-minute breathing space

$\begin{array}{lllll}\text { Daily } & 5-6 & 3-4 & 1-2 & \text { Never }\end{array}$ times times times

$\begin{array}{lllll}0 & 0 & 0 & 0 & 0\end{array}$

3-minute breathing space 
Walking meditation (e.g. when transitioning from one activity to another)

Attending to physical sensations (e.g. breathing) when your body is reacting to stress

Practicing non-judgmental awareness of thoughts (i.e. "just noticing" your thoughts)

Paying attention to emotional reactions (rather than getting "carried away")

Noticing that sense experiences arise from different "platforms" (body, sensations, thoughts or emotions)

4. Please provide an estimate of your average daily practice (in minutes) this past week.

\begin{tabular}{|c|c|c|c|c|c|c|}
\hline & $>50$ mins & $41-50$ & $31-40$ & $21-30$ & $11-20$ & $1-10$ \\
\hline Formal practices & 0 & 0 & 0 & 0 & 0 & 0 \\
\hline Informal practices & 0 & 0 & 0 & 0 & 0 & 0 \\
\hline
\end{tabular}

5. Are there any other activities, not listed above, that have helped you with your practice since completing the course? If so, please describe below:

a) List any activity that, for you, is either a mindful practice (not listed above) or helps you to sustain your mindfulness practice in general. Describe briefly and provide examples for activities that you engaged in during the week.

b) Please provide an estimate of your average daily practice (in minutes) for each of the activities listed in the previous question.

$$
\begin{array}{llllll}
>50 & 41-50 & 31-40 & 21-30 & 11-20 & 1-10
\end{array}
$$

First activity

Second activity

0


Third activity

Fourth activity

○

0

○

0

O

O

\section{Fourth activity}

0

O

6. We have asked you about your practice for this past week. Compared with the previous week, would you say the frequency of your practice this past week has been about the same, higher or lower

O About the same

O Higher

○ Lower

7. What is currently your biggest challenge or obstacle to keeping up your mindfulness practice?

8. What is a nagging question or concern that you have about mindfulness practice?

9. Please provide the same ID used for previous questionnaires. This will allow us to match your responses here with your previously submitted responses. All information remains confidential.

Your ID is your first and last initials followed by your date of birth (MMDDYY). 


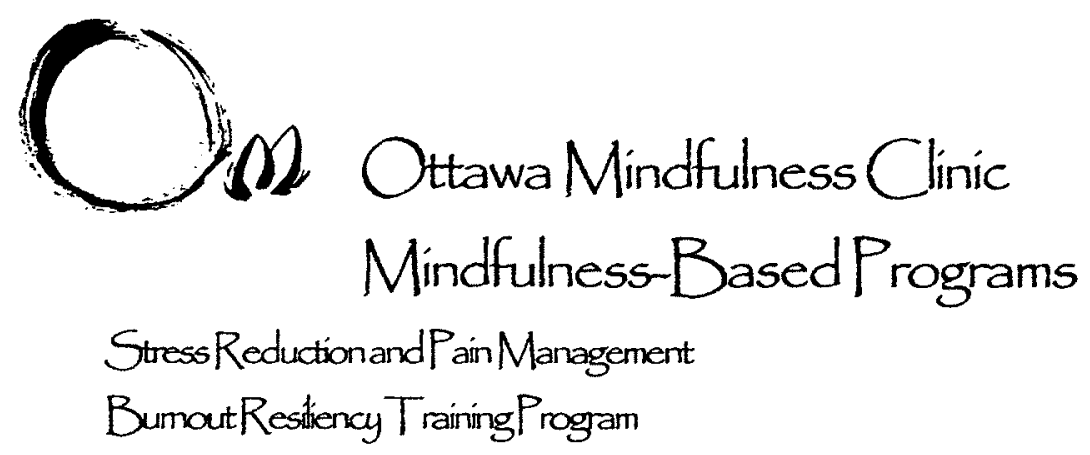

Welcome to the program, and thank you for participating in our course evaluation. We are interested in knowing how our participants relate to themselves, others, and their environments. Please complete the following questionnaires before beginning the course to assist us. We will ask that you complete the same set of questionnaires after completing the course as well.

The data gathered for this program evaluation are confidential and anonymous with respect to your personal identity. Please do not include your name on any of the questionnaires that you complete.

Instead, use the following ID on each of the questionnaires you complete.

Your ID: Initials (First, Last), and date of birth (MMDDYY)

For example: Howard Zinn d.o.b. 08/24/1922 ID\#: HZ082422

Thank you in advance for your cooperation. Your participation is valuable for helping us to learn more about how and why the program is effective and to improve future courses. If you have any questions about this program evaluation, please contact us and we will be happy to answer them. 


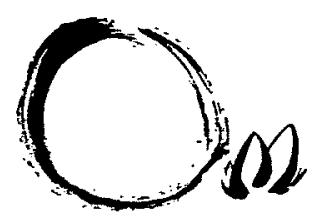

Ottawa Mindfulness Clinic Mindfulness-BasedPrograms

StressReduction and PainManagement

Bumout Restiency Training Progzam

Thank you for your participation in our program! We've enjoyed having you.

Please take the time to fill out the attached questionnaires. Your responses help us to evaluate the usefulness of the program for participants as well as the effectiveness of this mindfulness intervention.

As a reminder, if these data are used in research publications you are assured of anonymity in the use of your responses. That is, there exists no risk of identifying persons directly.

Please use the same ID as before: Initials (First, Last) and date of birth (MMDDYY)

For example: Clint Eastwood d.o.b. 05/31/1930 ID\#: CE053130

Thank you in advance for your cooperation. Please feel free to contact the clinic if you would like individual feedback on the results of your questionnaires. 

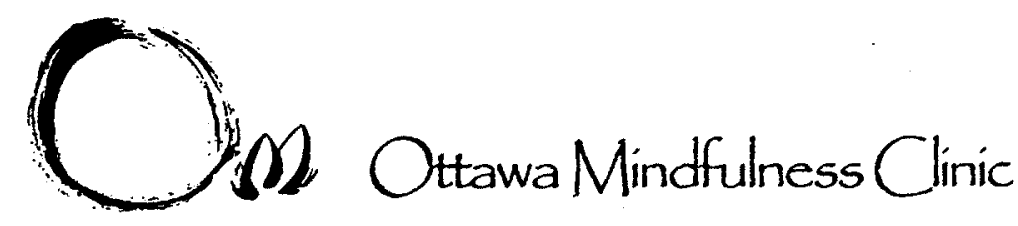

Mindfulness-BasedPrograms

StressReductionandP ainManagement

Bumout Restiency TrainingProgram

Thank you for your participation in our program evaluation. Enclosed are the final questionnaires for the 3-month follow-up. Your feedback will help us to evaluate the usefuiness and effectiveness of this mindfulness program over time.

Please return all forms as soon as possible. Once completed, kindly insert the questionnaires in the enclosed postage paid envelope and drop them in the mail.

As a reminder, if these data are used in research publications, you are assured of anonymity in the use of your responses. That is, there exists no risk of identifying persons directly. If you have any questions, we will be happy to answer them. Please feel free to contact the clinic.

Thank you in advance,

Lynette

$-$

Lynette Monteiro, Ph.D., C.Psych.

R. Frank Musten, Ph.D., C.Psych.

Ottawa Mindfulness Clinic

595 Montreal Road Suite 301

Ottawa ON K1K 4 L2

$6137455366 \quad 6137451186$ (fax)

www.ottawamindfulnessclinic.com 


\section{Appendix D: Figures}

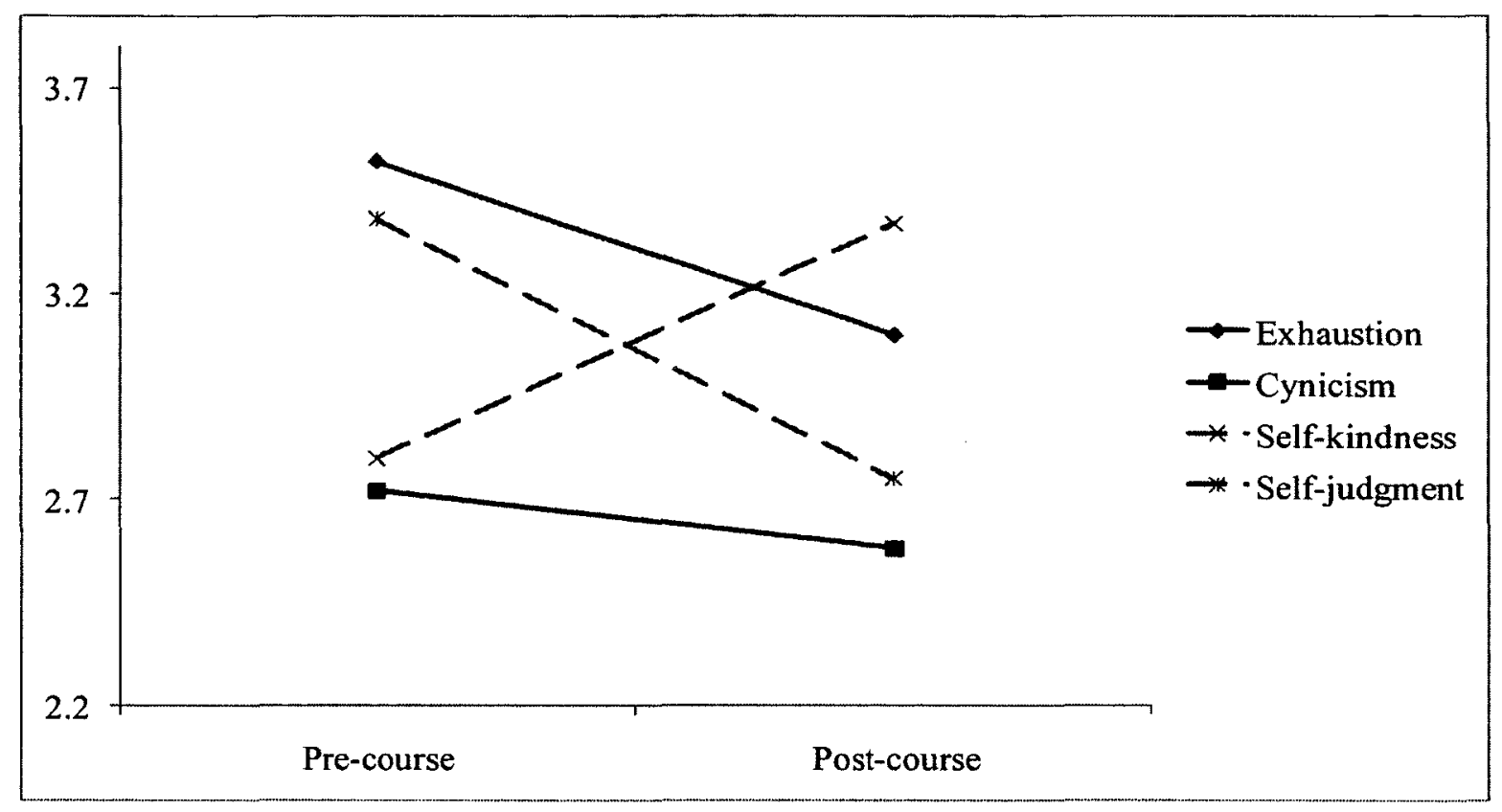

Figure D1. Graph of Levels of Exhaustion, Cynicism, Self-Kindness, and Self-Judgment at Pre- and Post-Course. 


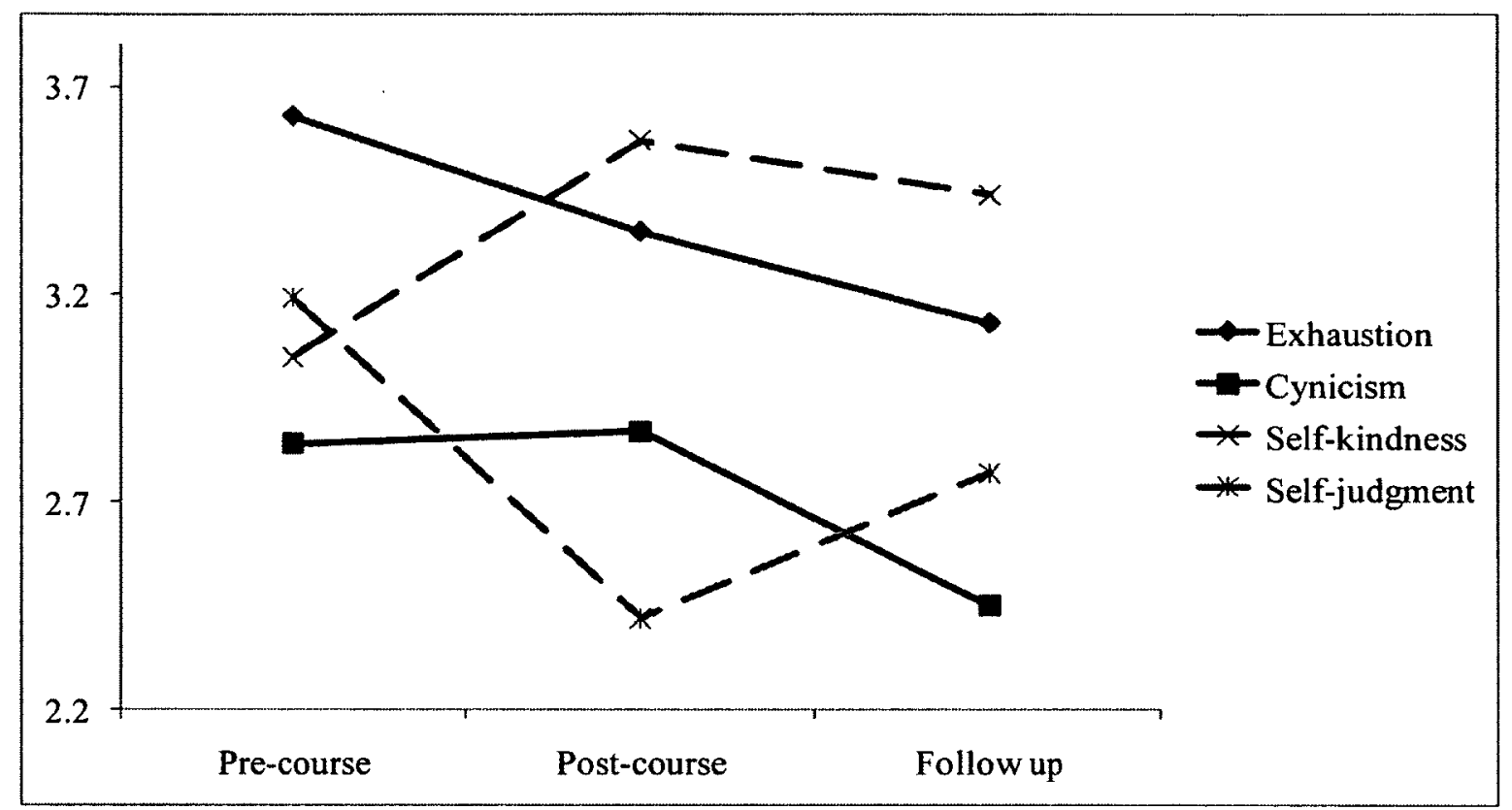

Figure D2. Graph of Levels of Exhaustion, Cynicism, Self-Kindness, and Self-Judgment at Pre-, Post-Course, and 3-Month Follow Up. 